\title{
La relación entre el Tercer Sector de Acción Social y las Administraciones Públicas. Una comparativa autonómica
}

\section{Eduardo Díaz Velázquez, Santiago García Campá, Luis Mancha San Esteban}

RESUMEN: El Tercer Sector de Acción Social (TSAS) se erige como un actor relevante en la coproducción de bienestar en el Welfare Mix, de forma interrelacionada con las Administraciones Públicas o, incluso, dependiente de la financiación de éstas. En los últimos años, las crisis económicas y la reconfiguración del ámbito de los servicios sociales con la creciente competencia del sector mercantil están redefiniendo el papel del TSAS en la provisión de servicios sociales. En el marco del proyecto Perspectiva Comparada del Tercer Sector de Acción Social en las Comunidades Autónomas (PECOTSAS), financiado por el Plan Estatal de Investigación del Ministerio de Economía, Industria y Competitividad (ref CS02017-85486-P), mediante una metodología cualitativa basada en entrevistas y grupos focales a expertos, profesionales y otros actores relevantes del TSAS y de la Administración, hemos analizado de forma comparativa el encaje institucional y social del TSAS en diferentes comunidades autónomas, para explorar si existen factores diferenciales en su desarrollo dentro de cada región. Este artículo se centra en concreto en las relaciones del TSAS con las administraciones autonómicas. En particular, analiza de forma comparativa la posición del TSAS en la legislación existente sobre servicios sociales en cada comunidad autónoma, las formas de colaboración económica predominantes para la prestación de servicios y el desarrollo de programas de acción social, así como la existencia de espacios para la participación del TSAS en la toma de decisiones relacionadas con el bienestar social.

PALABRAS CLAVE: Tercer Sector de Acción Social, estado de bienestar, comunidades autónomas, concierto social, mesas de diálogo.

CLAVES ECONLIT: L31, I38, H53, Z13. 
Cómo citar este artículo/How to cite this article: DÍAZ, E., GARCÍA, S. \& MANCHA, L. (2021): "La relación entre el Tercer Sector de Acción Social y las Administraciones Públicas. Una comparativa autonómica", CIRIEC-España, Revista de Economía Pública, Social y Cooperati$v a, 103,75-110$. DOI: 10.7203/CIRIEC-E.103.21522.

Correspondencia: Eduardo Díaz Velázquez, Universidad de Alcalá, eduardo.diazv@uah.es, ORCID: 0000-0002-7996-6566; Santiago García Campá, Universidad Jaume I, ORCID: 00000002-8887-2780; Luis Mancha San Esteban, Universidad de Alcalá.

ABSTRACT: The Third Sector of Social Action (TSSA) is a relevant actor in the co-production of welfare in the welfare mix, interrelated with public administrations and often dependent on their funding. In recent years, the economic crises and the reconfiguration of the field of social services with increasing competition from the market sector are redefining the role of the TSSA in the provision of social services. In the framework of the Comparative Perspective on the Third Sector of Social Action in the Autonomous Communities (PECOTSAS) project, funded by the State Research Plan of the Spanish Ministry of Economy, Industry and Competitiveness (ref CS02017-85486-P), we have comparatively analysed the institutional and social fit of the TSSA in different Autonomous Communities, to explore whether there are differential factors in its development within each region, using a qualitative methodology based on interviews and focus groups with experts, professionals and other relevant actors of the TSSA and the public administration. This article focuses specifically on the TSSA's relations with the regional administrations. In particular, it analyses comparatively the position of the TSSA in the existing legislation on social services in each Autonomous Community, the prevailing forms of economic collaboration for the provision of services and the development of social action programmes, as well as the existence of spaces for the participation of the TSSA in decision-making related to social welfare.

KEYWORDS: Third Sector of Social Action, welfare state, Autonomous Communities, social covenant, dialogue roundtables. 


\section{Expanded abstract}

\section{The relationship between the Third Sector of Social Action and the public administrations. A regional comparison}

In parallel to the development and consolidation of the welfare state in Spain since the 1980s, the Third Sector of Social Action (hereinafter, TSSA) has emerged as a dependent collaborator of social policies, adopting the role of service provider under a regulatory and funding framework conducive to its integration into a mixed welfare system. This has been articulated on the basis of a decentralised system, in which the Autonomous Communities (hereinafter, ACs) are responsible for the provision of education, health and social services. The decentralisation of the welfare state in Spain has had a certain impact on the intensity of protection in the different territories, as well as on the role that the TSSA has played both in the provision of welfare at the local and regional levels and in terms of territorial rebalancing. This reality has led some authors to suggest the hypothesis that the Third Sector, like the welfare state, has been configured relatively independently in each AC.

In the framework of the Comparative Perspective on the Third Sector of Social Action in the Autonomous Communities (PECOTSAS) project, funded by the State Research Plan of the Ministry of Economy, Industry and Competitiveness (ref CS02017-85486-P), we have analysed whether there are differential factors in the development of the TSSA within each region. In this article, we examine the relationships between the TSSA and the regional administrations along three dimensions: its presence in the legislation on social services, the predominant type of financial relationship for the provision of services and the channels established for the participation of the TSSA in public affairs.

To this end, a qualitative methodology was used based on 48 interviews and 14 focus groups with experts, professionals, volunteers and other relevant actors of the TSSA and of the administration in the ACs of Andalusia, Castile and Leon, Catalonia, Community of Madrid, Community of Valencia, Basque Country and Region of Murcia. In addition, an analysis of the regulations on social services in the aforementioned ACs was carried out.

The objective is to analyse the factors that influence the forms of relationship established between the TSSA and the administration and to identify possible differences between the ACs under analysis, in the indicated dimensions.

First, the regulatory impact on the TSSA takes into consideration four fundamental axes. Two primary axes correspond to the regulations governing social services and the specific regulation of the TSSA. Two secondary axes, which correspond to the regulatory development in two particular areas: social covenants (and by extension, the forms of financing) and the dialogue roundtables (and by extension, the forms of participation of the TSSA in institutional 
bodies). The analysis shows that regulatory advances in some ACs tend to be progressively incorporated in others, at the request of the TSSA itself or through the transfer of innovative practices from some administrations to others, in addition to being driven by state-wide legislation and, in the first instance, by European legislation, which sets a trend (social covenants, public procurement) that is being incorporated gradually and at different paces by all the ACs.

With regard to the forms of financial collaboration for the provision of social services, we have analysed three issues: the predominant forms of cooperation, the role of for-profit provision and the influence of the decentralisation of the $0.7 \%$ of personal income tax subsidies. In terms of the predominant forms of financial collaboration, the ACs are moving towards social covenants for the management of centres and services, although subsidies continue to predominate, especially to finance programmes. The trend suggests that the social covenant will gradually relegate subsidies as the main form of financing, since the subsidy model is not considered adequate to finance essential benefits of subjective right such as those managed by the TSSA, but at the same time public procurement, in which the commercial sector is hegemonic because the TSSA cannot compete with it on the basis of pricing, will progressively assume greater prominence. The weight of private for-profit provision compared to the TSSA in the provision of services depends to a large extent on the type of services and the group to which they are provided (the elderly, dependency or children being the preferred ones).

Thus, the penetration of the for-profit sector in one area or another depends on its profit expectations. Whether the for-profit sector is more or less established in the ACs depends on the strength of the TSSA in the region, its organisation into second- or third-level entities, the historical roots of collaboration with the administration and the political orientation of the regional governments, although the tendency is for the presence of for-profit companies to grow in all the ACs, under a rationale of commercialisation. On the other hand, the decentralisation of the management of the $0.7 \%$ personal income tax subsidies reverses the purpose of territorial structuring that these subsidies had in the past, making coordination and management of second-level entities difficult on the basis of economies of scale, and precluding the development of inter-territorial projects of wide-ranging scope. This decentralisation is perceived more positively in the peripheral communities (Valencia, Andalusia, Catalonia), Murcia and Castile and Leon. At the regional level, large organisations and federations have been affected by this change, losing weight in the receipt of funds to small and first-level entities, which were previously ineligible under the previous system, generating greater competition for resources, but also an increase in the workload (for entities that previously received funding via federations, but did not manage the process). In the case of the regional administrations, the change can be interpreted as positive in that it provides funds with a greater degree of proximity and enables administrations to adapt funding to their technical or political priorities (but also to strengthen clientelist networks). In any case, the continuity underlying its implementation has not lived up to expectations, as it has not distanced itself so far from previous forms of financing as to generate significant transformations in the regional TSSA.

With regard to the participation of the TSSA in public affairs, factors such as the existence or not of dialogue roundtables or other channels for participation; their constitution process, 
i.e. whether it was at the initiative of the administration or the TSSA; the geographical distribution of the sector, e.g. with regard to the centre-periphery dialectic; the internal cohesion of the sector and its organisation around representative platforms; the existence of second-level organisations (federations); the relevance and nature of informal channels (social capital); as well as the presence of entrenched social capital (social capital); and the entrenchment of an associative culture in the ACs. In any event, the tendency is for the ACs to institutionalise the participation of the TSSA in public affairs by creating dialogue roundtables or equivalent bodies, although they do so at different rates and with different characteristics, which is fundamentally influenced by the strength of the TSSA in that region and its capacity to organise around platforms that provide them with a single voice.

In conclusion, the TSSA and the public administrations are developing a necessary but economically dependent form of cooperation. In all the ACs, there is a growing penetration of the market logic in the provision of social services, albeit at different rates and intensities in each of them. This commodifying rationality is not only confined to service procurement (with pricing taking precedence over quality or social clauses) but, as an objectifiable criterion for the allocation of funds or resources, it is also being transferred to covenants and subsidies, under market-based competitive logics that are gradually forcing TSSA entities to adopt management-based organisational forms that may well distort their very identity. In this tension underlying the TSSA-public administrations-market trinomial, the TSSA is struggling to define its own space in the field of social services, with legislation (as a performance-oriented instrument) being one of the key frameworks in which this struggle for formal recognition of its preferential role as a service provider takes place. This occurs either by providing it with economic stability and security, through formulas such as covenants; or by providing it with legitimacy as a valid interlocutor with the administration, through the dialogue roundtables, which essentially serve to defend its interests, in the manner of a Third Sector employers' association. In this transformation, the TSSA runs the risk of losing part of its identity, whether at the technical level, by subordinating itself to the intervention model of the public network; at the relational level, through the loss of the linkages that had sustained many entities until then; or at the political level, by subordinating its advocacy or defence of the groups it represents to the iron chains of its financial dependence. 


\section{Introducción}

Entendemos por tercer sector el conjunto de las organizaciones de la economía social (cooperativas, mutuas y sociedades laborales) y las organizaciones sin fin de lucro (asociaciones o fundaciones) (Salinas, Rubio y Cerezo, 2001). En este artículo analizaremos en concreto el tercer sector de acción social (en adelante, TSAS), que engloba a las entidades dedicadas a la intervención social con colectivos vulnerables o en riesgo de exclusión. En base a la definición aprobada por el Consejo Estatal de ONG de Acción Social, este TSAS estaría formado por entidades privadas de carácter voluntario y sin ánimo de lucro que, surgidas de la libre iniciativa ciudadana, funcionan de forma autónoma y solidaria tratando, por medio de acciones de interés general, de impulsar el reconocimiento y el ejercicio de los derechos sociales, de lograr la cohesión y la inclusión social en todas sus dimensiones y de evitar que determinados colectivos sociales queden excluidos de unos niveles suficientes de bienestar (Fundación Luis Vives, 2010, 2012; POAS, 2015, 2020). Esta definición engloba a asociaciones y fundaciones de acción social, las entidades denominadas singulares (ONCE, Cruz Roja y Cáritas), entidades de segundo y tercer nivel (federaciones autonómicas que agrupan entidades y confederaciones estatales que agrupan a éstas, así como plataformas de representación) y centros especiales de empleo y empresas de inserción dependientes de asociaciones o fundaciones.

En paralelo al desarrollo y consolidación del Estado de Bienestar en España desde los años 80 del siglo XX, el TSAS se ha erigido como colaborador dependiente de las políticas sociales, adoptando un papel de proveedor de servicios bajo un marco regulador y de financiación propicio a su integración en un régimen de bienestar mixto (Marbán y Rodríguez Cabrero, 2013). Un régimen de bienestar que se ha articulado a partir de un sistema autonómico, descentralizado, en el que son las comunidades autónomas (en adelante, CCAA) las que cuentan con las competencias en la provisión de la educación, la salud o lo servicios sociales. La descentralización del Estado de Bienestar en España ha tenido cierto impacto en la intensidad de la protección en los distintos territorios, así como en el papel que el TSAS ha tenido tanto en la provisión de bienestar a nivel local y regional, sobre todo entre las entidades pequeñas y medianas, como en el reequilibrio territorial, realizado por las grandes entidades a nivel estatal (Rodríguez Cabrero y Marbán, 2015), al menos hasta la descentralización de las subvenciones del $0,7 \%$ del IRPF a las CCAA.

Esta realidad ha propiciado que algunos autores sugirieran la hipótesis de que el tercer sector, al igual que lo ha hecho el Estado de Bienestar, se ha configurado de manera relativamente independiente en cada comunidad autónoma (Aguiar y Pérez Yruela, 1995: 216). En todo caso, la relación del TSAS con las administraciones autonómicas va a explicar tanto su desarrollo como su posición y configuración dentro del sistema mixto de bienestar de esa comunidad (Marbán y Rodríguez Cabrero, 2013).

En el marco del proyecto Perspectiva Comparada del Tercer Sector de Acción Social en las Comunidades Autónomas (PECOTSAS), financiado por el Plan Estatal de Investigación del Ministerio de Economía, Industria y Competitividad (ref CS02017-85486-P) hemos analizado de forma comparativa el encaje institucional y social del TSAS en diferentes comunidades autóno- 
mas, para explorar si existen factores diferenciales en su desarrollo dentro de cada región. En particular, en este artículo examinamos las relaciones entre el TSAS y las administraciones autonómicas, en base a tres dimensiones: la presencia del TSAS en su legislación sobre servicios sociales, el tipo de relación financiera predominante (concertación, contratación, subvención) para la prestación de servicios, así como los canales que se establecen para la participación del TSAS en los asuntos públicos.

Existe una amplia literatura tanto internacional como nacional que ha analizado las relaciones entre administraciones públicas y tercer sector, sintetizada por Prieto et al. (2019). pero que, como estos autores señalan, han abordado el fenómeno fundamentalmente desde un punto de vista teórico, no tanto empírico, sobre todo a escala regional y local (Prieto et al., 2019: 69). Este trabajo pretende realizar un análisis empírico sobre las relaciones entre el TSAS y la administración pública en varias CCAA españolas.

\section{Metodología}

Para llevar a cabo esta investigación se ha utilizado una metodología cualitativa basada en 48 entrevistas en profundidad y 14 grupos focales a expertos, profesionales, voluntarios y otros actores relevantes del TSAS y de la Administración en las CCAA de Andalucía, Castilla y León, Cataluña, Comunidad de Madrid, Comunidad Valenciana, País Vasco y Región de Murcia. La selección de las CCAA se ha realizado teniendo en cuenta criterios como el desarrollo económico, el tamaño, estructura territorial y administrativa y el grado de implantación del TSAS en dichos territorios que, según datos de García Delgado (2005), abarcarían aproximadamente el $70 \%$ de las entidades del TSAS. Las entrevistas en profundidad se realizaron a lo largo de 2019 y los grupos focales, previstos para el primer semestre de 2020, debido a la crisis pandémica de Covid-19 finalmente se realizaron en modalidad online entre abril y mayo de 2019.

En la selección de informantes se ha tenido en cuenta su experiencia académica e investigadora en el ámbito del TSAS, en la gestión de servicios sociales autonómicos o municipales o bien en la intervención social en el TSAS.

La relación de informantes por perfiles y por CCAA se detalla en la tabla 1.

En cuanto a los grupos focales, se han realizado dos por cada comunidad autónoma seleccionada, formados por profesionales mandos intermedios de entidades del TSAS y por voluntarios, respectivamente. 
Tabla 1. Relación de entrevistas en profundidad por comunidades autónomas, perfiles de informantes y código de las entrevistas

\begin{tabular}{|c|c|c|c|}
\hline COMUNIDAD & PERFIL DE INFORMANTES & $\begin{array}{l}\text { ENTREVISTAS } \\
\text { REALIZADAS }\end{array}$ & CóDIGOS \\
\hline \multirow[t]{2}{*}{ Andalucía } & Profesionales del sector & 4 & \multirow[t]{2}{*}{ E01-06 } \\
\hline & Expertos y otros informantes & 2 & \\
\hline \multirow[t]{2}{*}{ Comunidad de Madrid } & Profesionales del sector & 3 & \multirow[t]{2}{*}{ E07-15 } \\
\hline & Expertos y otros informantes & 6 & \\
\hline \multirow[t]{2}{*}{ País Vasco } & Profesionales del sector & 5 & \multirow[t]{2}{*}{ E16-24 } \\
\hline & Expertos y otros informantes & 3 & \\
\hline \multirow[t]{2}{*}{ Cataluña } & Profesionales del sector & 5 & \multirow[t]{2}{*}{$E 25-32$} \\
\hline & Expertos y otros informantes & 3 & \\
\hline \multirow[t]{2}{*}{ Castilla y León } & Profesionales del sector & 3 & \multirow[t]{2}{*}{ E33-38 } \\
\hline & Expertos y otros informantes & 3 & \\
\hline \multirow[t]{2}{*}{ Comunidad Valenciana } & Profesionales del sector & 3 & \multirow[t]{2}{*}{ E39-43 } \\
\hline & Expertos y otros informantes & 2 & \\
\hline \multirow[t]{2}{*}{ Región de Murcia } & Profesionales del sector & 3 & \multirow[t]{2}{*}{ E44-48 } \\
\hline & Expertos y otros informantes & 2 & \\
\hline
\end{tabular}

Fuente: Elaboración propia.

Para completar el análisis, se ha realizado un análisis de la normativa sobre servicios sociales de las citadas CCAA en lo que concierne al tercer sector.

El objetivo de este artículo es analizar cuáles son los factores que influyen en las formas de relación que se establecen entre el TSAS y la Administración e identificar posibles diferencias entre las comunidades autónomas analizadas. 
Tabla 2. Relación de grupos focales por comunidades autónomas, perfiles y código

\begin{tabular}{|c|c|c|c|}
\hline COMUNIDAD & GRUPO FOCAL & PARTICIPANTES & cóDIGOS \\
\hline \multirow[t]{2}{*}{ Andalucía } & Mandos Intermedios & 4 & GF03 \\
\hline & Voluntarios/as & 7 & GF05 \\
\hline \multirow[t]{2}{*}{ Comunidad de Madrid } & Mandos Intermedios & 6 & GFO4 \\
\hline & Voluntarios/as & 5 & GF01 \\
\hline \multirow[t]{2}{*}{ País Vasco } & Mandos Intermedios & 6 & GF13 \\
\hline & Voluntarios/as & 6 & GF14 \\
\hline \multirow[t]{2}{*}{ Cataluña } & Mandos Intermedios & 4 & GF10 \\
\hline & Voluntarios/as & 5 & GF06 \\
\hline \multirow[t]{2}{*}{ Castilla y León } & Mandos Intermedios & 6 & GF07 \\
\hline & Voluntarios/as & 5 & GFO2 \\
\hline \multirow[t]{2}{*}{ Comunidad Valenciana } & Mandos Intermedios & 3 & GF08 \\
\hline & Voluntarios/as & 2 & GF09 \\
\hline \multirow[t]{2}{*}{ Región de Murcia } & Mandos Intermedios & 3 & GF11 \\
\hline & Voluntarios/as & 2 & GF12 \\
\hline
\end{tabular}

Fuente: Elaboración propia.

\section{El TSAS en la normativa autonómica sobre servicios sociales. Comparativa e impacto}

A partir del análisis de la legislación existente y de las percepciones y valoraciones expresadas sobre ésta en las entrevistas y grupos focales realizados en las CCAA analizadas, podemos observar que el mayor o menor desarrollo normativo, así como su orientación, influye en la configuración del TSAS en cada comunidad autónoma.

La regulación del TSAS se considera necesaria, de manera general entre los entrevistados (con diferencias en función de sus niveles de responsabilidad), pues dota al sector de seguridad jurídica, le proporciona un marco definido para relacionarse con la Administración Pública autonómica y define los papeles que corresponden a las empresas lucrativas y las entidades 
no lucrativas (E1, E18, E20, E33, E36). El tratamiento legal de estas tres cuestiones se estima relevante en la medida que materializa la orientación ideológica de quien ocupa el poder legislativo y ejecutivo en cada momento (E41).

La complejidad del marco jurídico aplicable se repite en las CCAA estudiadas, en la medida que en todas ellas coexisten: a) normas de ámbito estatal, que regulan el régimen jurídico aplicable a la organización y el funcionamiento de las asociaciones (Ley Orgánica 1/2002, de 22 de marzo) y las fundaciones (Ley 50/2002, de 26 de diciembre), pero también a su actividad mediante las leyes estatales sobre subvenciones (Ley 38/2003, de 17 de noviembre) y contratos públicos (Ley 9/2017, de 8 de noviembre); b) normas de ámbito autonómico, que adaptan la normativa anterior (p.ej., Ley 4/2006, de 23 de junio, de Asociaciones de Andalucía o Ley 9/2016, de 2 de junio, de Fundaciones del País Vasco) o que desarrollan leyes en materia de servicios sociales exclusivamente propias ${ }^{1}$, al ser competencia exclusiva autonómica, condicionando la forma de colaboración con el TSAS en cada territorio (Rodríguez Cabrero y Marbán, 2015); y c) normas de ámbito local reguladoras fundamentalmente de convocatorias de ayudas, de procedencia tanto provincial como municipal (GF10). Precisamente, el desarrollo de estos dos últimos planos normativos proporciona ciertas diferencias entre TSAS autonómicos, pero sin desembocar en un modelo completamente diferenciado de otras CCAA: así, por ejemplo, en Castilla y León, la Red de protección e inclusión a personas y familias en situación de mayor vulnerabilidad social o económica (Ley 4/2018, de 2 de julio), ha mejorado el acceso a la financiación pública del sector (E34, E37), pero sin llegar a modificar su constitución general; o, en el País Vasco, el papel que tienen las Diputaciones Forales en materia social (Ley $27 / 1983$, de 25 de noviembre), hasta el punto de que el TSAS de cada territorio cuente con características distintas (E18), pero sin llegar a producir un modelo de TSAS propio, al menos si se compara con las diferencias que pueden existir entre provincias de otras Comunidades como, por ejemplo, Andalucía (E16).

El impacto en el TSAS de la normativa existente toma en consideración cuatro ejes fundamentales. Los dos primeros ejes, que podemos calificar primarios, se corresponden con dos leyes claramente identificadas en todos los territorios: la que regula los servicios sociales y la que regula específicamente el TSAS. Los dos ejes restantes, que podemos calificar secundarios o sub-ejes, se corresponden con el desarrollo reglamentario en dos materias particulares: por un lado, los conciertos sociales (o, por extensión, las formas de financiación) y, por otro, las mesas de diálogo entre el TSAS y la Consejería competente en materia de servicios sociales (E1, E5, E18, E20, E34, E35) o, por extensión, las formas de participación del TSAS en los órganos institucionales que se creen a tal efecto.

En el primer eje, la relevancia de la regulación legislativa sobre servicios sociales es una constante, lo que resulta lógico teniendo en cuenta el ámbito de actuación del TSAS. En el contenido de esta regulación se valora especialmente, en primer lugar, el reconocimiento singular

1. Ley $3 / 2019$, de 18 de febrero, de la Generalitat, de Servicios Sociales Inclusivos de la Comunitat Valenciana; Ley 12/2007, de 11 de octubre, de Servicios Sociales de Cataluña; Ley 11/2003, de 27 de marzo, de Servicios Sociales de la Comunidad de Madrid; Ley 9/2016, de 27 de diciembre, de Servicios Sociales de Andalucía; Ley 16/2010, de 20 de diciembre, de servicios sociales de Castilla y León; Ley 12/2008, de 5 de diciembre, de Servicios Sociales del País Vasco o la recientemente aprobada Ley 3/2021, de 29 de julio, de Servicios Sociales de la Región de Murcia. 
del TSAS como agente de acción social y, en segundo lugar, su papel no solo en la prestación de servicios sociales, sino también en su diseño y evaluación (E5, E18, E19, E41). En los textos legales sobre servicios sociales se estima particularmente la inclusión de mecanismos de colaboración del TSAS en la prestación de servicios sociales distintos de las subvenciones: contratos, convenios, acuerdos de colaboración y, en las leyes de servicios sociales más recientes, los conciertos sociales (E1, E19, E26, E34, E42, E43). Precisamente, como primer sub-eje, la utilización de los conciertos sociales con el TSAS como mecanismo principal para la prestación de servicios públicos permite diferenciar entre las CCAA que han desarrollado este mecanismo reglamentariamente [Comunidad Valenciana (Decreto 181/2017, de 17 de noviembre), Cataluña (Decreto 69/2020, de 14 de julio), Murcia (Decreto 10/2018, de 14 de febrero) y Andalucía (Decreto 41/2018, de 20 de febrero)] y aquellas que no lo han hecho todavía [Madrid, Castilla y León y País Vasco]. En el primer grupo, donde existe un Decreto regulador de los conciertos sociales, los conciertos sociales son valorados de manera muy positiva, sobre todo porque estabilizan la financiación, los recursos y los centros del TSAS (E19, E26, R34, E42, E43). No obstante, se advierte claramente sobre el riesgo de que este instrumento convierta el TSAS en un mero gestor de la Administración Autonómica (E42). En el segundo grupo de CCAA, cuya regulación reglamentaria de los conciertos sociales está en tramitación o cuya discusión está iniciándose, buena parte de las expectativas de crecimiento y mejora del TSAS están depositadas en su regulación normativa, pues se considera que puede consolidar la colaboración del TSAS con la Administración Pública (E26, E34). Las dificultades para desarrollar una normativa de concierto social que consolide la colaboración público-privada con el TSAS, que respete la Directiva 2014/24/UE sobre contratación pública, que permita evaluar los resultados de lo financiado y que no tenga resquicios legales explican en cierto modo el retraso en la aprobación de estas normas en algunas de las CCAA. Es por eso que la clasificación de las CCAA según si cuenta o no con normativa sobre el concierto social es claramente provisional, pues el TSAS de los territorios que carecen de ella aspira a que se apruebe un texto reglamentario, lo que convierte este factor diferencial en un factor de homogeneización entre Comunidades con el paso del tiempo: la regulación existente en una comunidad autónoma que favorece al TSAS es demandada por el TSAS en aquella comunidad que carece de dicha normativa, lo que neutraliza su impacto como factor de diferenciación bajo una perspectiva temporal. Es decir, los avances normativos en unas CCAA tienden progresivamente a ser incorporados en otras, bajo demanda del propio TSAS o por transferencia de prácticas innovadoras de unas administraciones a otras.

El segundo eje viene dado por la existencia de una normativa específica reguladora del TSAS, que solo está vigente en el País Vasco (Ley 6/2016, de 12 de mayo). El efecto, de nuevo, es imitativo en el TSAS del resto de Comunidades Autónomas, que aspira a contar con un texto legislativo autonómico propio que lo reconozca jurídicamente, le dé carta de naturaleza y lo proteja (E13, E20, E34), lo que redunda en el impacto normativo homogeneizador entre CCAA ya apuntado.

De manera solo relativamente dependiente surge como segundo sub-eje la regulación jurídica de un espacio u órgano de participación administrativa del TSAS, bajo la denominación de 
Mesa de diálogo social en Madrid (Decreto 56/2019, de 18 de junio), la Comisión Permanente de Diálogo con la Mesa del Tercer Sector en Andalucía (Decreto 98/2016, de 10 de mayo), Mesa de apoyo al Tercer Sector de la Región de Murcia (Orden de 9 de septiembre de 2015)2, Mesa de Diálogo Civil en la Comunidad Valenciana (Ley 3/2019, de 18 de febrero) o Mesa de diálogo civil en el País Vasco (Decreto 283/2012, de 11 de diciembre). Decíamos que la relación es solo relativamente dependiente porque, si bien donde existe Ley específica sobre el TSAS se regula este espacio de encuentro (País Vasco), también está previsto en comunidades que no cuentan con Ley propia reguladora del TSAS, incorporada en su normativa sobre servicios sociales (Andalucía, Madrid) o en decretos ad hoc para institucionalizarlas (Murcia, Comunidad Valenciana). Esta relación directa parece todavía menor si se aprecia que una interlocución directa e incluso una mayor influencia del TSAS con la Administración Autonómica puede existir sin una Ley específica ni un órgano de consulta en funcionamiento, por el peso que puedan tener las plataformas asociativas, como ocurre con la Taula del Tercer Sector en Cataluña (E27).

A nivel estatal, las leyes sobre asociaciones y fundaciones no parece que tengan un impacto relevante ni diferencial a la hora de dar lugar a distintos modelos autonómicos de TSAS, así como la Ley 43/2015, de 9 de octubre, del Tercer Sector de Acción Social. Tampoco la legislación que podemos denominar instrumental, formada por la Ley de subvenciones y la Ley de contratos del sector público, parece condicionar el TSAS en las CCAA estudiadas, a pesar de su importancia en las condiciones en que se desenvuelve la actuación del TSAS financiada con fondos públicos. Esa regulación básica a nivel estatal tanto en materia de subvenciones como en materia de contratación pública, procedente a su vez de la Directiva europea 2014/24/UE, de 26 de febrero, ha de ser desarrollada y, fundamentalmente, ejecutada por cada comunidad autónoma. Es por tanto la propia legislación estatal y, en primera instancia, la legislación europea, la que va marcando una tendencia (el concierto social, la contratación pública, etc.) que, paulatinamente y a distintos ritmos, van incorporando todas las CCAA. El impacto de la regulación de las subvenciones radica sobre todo en su predominio para la financiación de programas (GF08) y en la baja tensión que producen con respecto a las empresas mercantiles, a pesar de estar sometidas a la incertidumbre y a la demora de la financiación. De manera opuesta, es en el marco normativo sobre los contratos públicos donde la tensión entre las empresas lucrativas y la lógica de la acción social sin ánimo de lucro es más intensa (E27). Esta tensión se decanta en favor de las compañías lucrativas por dos motivos: por una parte, porque el precio más bajo termina siendo el factor determinante para decidir la adjudicación de las licitaciones; y, por otra parte, porque el peso de las cláusulas sociales es residual (E4, E13, E19, E27, E30).

2. En la reciente Ley 3/2021, de 29 de julio se ha creado la Mesa de Diálogo Civil del Tercer Sector de Acción Social de la Región de Murcia. 
Tabla 3. Síntesis de la legislación principal sobre tercer sector en las CCAA analizadas

\begin{tabular}{|c|c|}
\hline COMUNIDAD & REFERENCIAS LEGISLATIVAS \\
\hline Andalucía & $\begin{array}{l}\text { - Ley 4/2006, de } 23 \text { de junio, de Asociaciones de Andalucía } \\
\text { - Ley 9/2016, de } 27 \text { de diciembre, de Servicios Sociales de Andalucía } \\
\text { - Decreto 98/2016, de } 10 \text { de mayo, por el que se crea la Comisión } \\
\text { Permanente de Diálogo con la Mesa del Tercer Sector de Andalucía } \\
\text { - Decreto 41/2018, de } 20 \text { de febrero, por el que se regula el concierto } \\
\text { social para la prestación de los servicios sociales }\end{array}$ \\
\hline $\begin{array}{l}\text { Comunidad de } \\
\text { Madrid }\end{array}$ & $\begin{array}{l}\text { - Ley 11/2003, de } 27 \text { de marzo, de Servicios Sociales de la Comunidad de } \\
\text { Madrid } \\
\text { - Decreto 56/2019, de } 18 \text { de junio, del Consejo de Gobierno, por el que se } \\
\text { crea la Mesa de Diálogo Civil de la Comunidad de Madrid con el Tercer } \\
\text { Sector de Acción Social }\end{array}$ \\
\hline País Vasco & $\begin{array}{l}\text { - Ley } 12 / 2008 \text {, de } 5 \text { de diciembre, de Servicios Sociales del País Vasco. } \\
\text { - Decreto 283/2012, de } 11 \text { de diciembre, por el que se constituye y regula } \\
\text { la Mesa del Diálogo Civil } \\
\text { - Ley 6/2016, de } 12 \text { de mayo, del Tercer Sector Social de Euskadi }\end{array}$ \\
\hline Cataluña & $\begin{array}{l}\text { - Ley } 12 / 2007 \text {, de } 11 \text { de octubre, de Servicios Sociales de Cataluña } \\
\text { - Decreto 69/2020, de } 14 \text { de julio, de acreditación, concierto social y } \\
\text { gestión delegada en la Red de Servicios Sociales de Atención Pública }\end{array}$ \\
\hline Castilla y León & $\begin{array}{l}\text { - Ley } 16 / 2010 \text {, de } 20 \text { de diciembre, de servicios sociales de Castilla y León } \\
\text { - Ley } 4 / 2018 \text {, de } 2 \text { de julio, de ordenación y funcionamiento de la red } \\
\text { de protección e inclusión a personas y familias en situación de mayor } \\
\text { vulnerabilidad social o económica en Castilla y León }\end{array}$ \\
\hline $\begin{array}{l}\text { Comunidad } \\
\text { Valenciana }\end{array}$ & $\begin{array}{l}\text { - Ley 3/2019, de } 18 \text { de febrero, de la Generalitat, de Servicios Sociales } \\
\text { Inclusivos de la Comunitat Valenciana } \\
\text { - Decreto } 181 / 2017 \text {, de } 17 \text { de noviembre, del Consell, por el que se } \\
\text { desarrolla la acción concertada para la prestación de servicios sociales } \\
\text { en el ámbito de la Comunitat Valenciana por entidades de iniciativa } \\
\text { social }\end{array}$ \\
\hline Región de Murcia & $\begin{array}{l}\text { - Ley } 3 / 2021 \text {, de } 29 \text { de julio, de Servicios Sociales de la Región de Murcia } \\
\text { - Decreto } 10 / 2018 \text {, de } 14 \text { de febrero, por el que se establece el régimen } \\
\text { jurídico de los conciertos sociales en la Región de Murcia en los } \\
\text { servicios sociales especializados en los sectores de personas mayores } \\
\text { y personas con discapacidad }\end{array}$ \\
\hline
\end{tabular}

Fuente: Elaboración propia. 


\section{Formas de colaboración económica entre el TSAS y las AAPP para la prestación de servicios sociales. Comparativa autonómica}

Las formas de colaboración económica que se establecen entre administración y TSAS para la prestación de servicios pueden influir en la configuración y desarrollo del TSAS. Estas formas de colaboración difieren entre las CCAA analizadas. En todo caso, lo que prevalece como denominador común es la consolidación de un welfare mix (Herrera Gómez, 2001; Comisión Europea, 2010; Marbán et al, 2020) a lo largo de los últimos años en torno a la prestación de servicios sociales en el que el TSAS ha tenido un papel importante, pero que a su vez ha visto cómo progresivamente el sector privado lucrativo, más en unas CCAA que otras, ha ido ganando peso en la gestión de servicios sociales públicos mediante fórmulas de contratación, sobre todo en servicios especializados para colectivos concretos (residencias de mayores, centros de día, centros de menores, etc.), en los cuales existe mayor margen de beneficio.

Podemos identificar al menos tres cuestiones clave a la hora de analizar la cooperación económica que se establece entre las Administraciones autonómicas y el TSAS para la prestación de servicios sociales, las cuales serían: 1) Las formas de colaboración financiera público-privada predominantes en cada comunidad. 2) El papel y el peso que tiene la oferta privada lucrativa. 3) La influencia que ha tenido la descentralización de las subvenciones del 0,7\% del IRPF en la financiación del TSAS.

Si atendemos a las formas de colaboración financiera predominantes, podemos observar, como ya hemos mencionado en el punto anterior, que en las CCAA se está avanzando hacia el concierto social; en unas de forma exclusiva para las entidades del TSAS, en otras abierto para entidades privadas del sector mercantil (Fresno, 2021). Sin embargo, sigue predominando la subvención. Si bien el concierto social mejora la financiación y estabilidad de las entidades para el desarrollo de su actividad, no está exento de riesgos legales, sobre todo cuando es en exclusiva o de forma preferente con entidades de iniciativa social. Riesgos legales que las empresas lucrativas están intentando activar si ven lesionados sus intereses. "Si tú ya empiezas a desarrollarlo vas a mover intereses, por ejemplo, de empresas privadas tradicionales de carácter capitalista, que te ponen su denuncia o su demanda" (E39). En todo caso, la tendencia apunta a que el concierto social irá relegando paulatinamente a la subvención como forma de financiación principal, ya que el modelo de subvenciones no es considerado adecuado por los diferentes actores para financiar prestaciones esenciales de derecho subjetivo como las que muchas veces gestiona el TSAS, que requieren una continuidad y estabilidad en la prestación, si bien las subvenciones puedan seguir financiando proyectos innovadores o que atiendan realidades emergentes. 
Entre las que cuentan ya con una normativa específica sobre concierto social, en el caso de la Comunidad Valenciana se ha restringido de manera exclusiva a las entidades de iniciativa social (Decreto 181/2017, de 17 de noviembre), lo que ha permitido abrir un espacio libre de la competencia del sector mercantil. Su generalización ha supuesto para las entidades una vía para la estabilización y "la modernización del sector según criterios de profesionalidad" (E41), reduciendo la arbitrariedad previa de un sistema de subvenciones, en muchos casos nominativas, basado en lógicas clientelares, sin criterios claros de adjudicación y que no financiaba el coste total de la actividad. Para la Administración, ha permitido poner orden y articular estos recursos con la red pública de servicios sociales. Casi todos los entrevistados y participantes en grupos focales lo ven positivamente, si bien el proceso de acreditación previo al concierto social no está exento de dificultades, sobre todo para las entidades pequeñas: "tardamos como tres años en conseguir la autorización de funcionamiento" (GF08). Sin embargo, proyectos y programas, que se siguen financiando mediante subvenciones de concurrencia competitiva, continúan con la misma incertidumbre: "Mandas un proyecto y no sabes si te lo van a financiar o no, pero tú lo tienes que poner en marcha sí o sí porque cuando la subvención llega tú tienes que justificar el $100 \%$ del proyecto que has solicitado" (GF08).

En Andalucía, aunque la legislación reconoce al tercer sector como actor preferente en la prestación de servicios públicos mediante concierto social (Decreto 41/2018, de 20 de febrero), la modalidad de financiación que prevalece según los entrevistados es la subvención, que implica también incertidumbre. La expectativa del TSAS es que primen en el futuro otras formas de colaboración más estables contempladas en la normativa, como los convenios y, sobre todo, los conciertos.

En el caso de Cataluña se ha regulado recientemente el concierto social (Decreto 69/2020, de 14 de julio), pero a juicio de los entrevistados actualmente predomina la subvención sobre cualquier otra forma de colaboración económica, sobre todo en organizaciones medianas y pequeñas y en el ámbito local.

En la Región de Murcia se restringió el concierto social a servicios dirigidos a personas mayores y personas con discapacidad, por lo que en la actualidad se persigue su extensión a otros servicios sociales especializados, tal y como plasma la nueva Ley 3/2021, de 29 de julio, pendiente aún de desarrollo reglamentario. El mecanismo fundamental sigue siendo la subvención, que genera problemas de financiación relativos al retraso en la concesión y el envío de los fondos, y genera precariedad laboral e inestabilidad e incertidumbre económica. Los contratos no son vistos como algo deseable, pues en ellos acaba primando la puja a la baja del precio y el sector lucrativo suele tener menos problemas para competir por precios.

En Castilla y León está en fase de elaboración el Decreto por el que se regula el régimen jurídico del concierto social, que genera recelos por su concurrencia competitiva y apertura al sector mercantil. No obstante, en la práctica el concierto está ganando peso en los últimos años, lo que dota de estabilidad a las entidades, aunque con diferencias según el sector de intervención y su capacidad instalada en la prestación de servicios. Así, en el ámbito de la discapacidad el proceso de transformación de las subvenciones en conciertos fue anterior al resto de organizaciones por su papel en la prestación de servicios y dotación de plazas en el marco 
del SAAD. Por lo tanto, hoy en día sigue siendo la subvención la forma de financiación predominante, antes de forma directa y cada vez más en concurrencia competitiva, que a pesar de las incertidumbres que implican, tienen menos riesgos y un mayor margen de discrecionalidad administrativa que los conciertos. Recibirlas supone entrar en la Red de protección e inclusión a personas y familias en situación de mayor vulnerabilidad social o económica y formar parte del sistema de responsabilidad pública de Servicios Sociales.

En el País Vasco, el concierto social se encuentra en proceso de regulación, en cuyo proyecto de decreto también está prevista la regulación de los convenios. La colaboración financiera entre TSAS y Administración autonómica (aunque en la financiación también es notable el peso de las Diputaciones) se ha ido modificando en los últimos años, lo que ha suscitado controversias en las entidades del TSAS. Históricamente, predominaba el uso de convenios, seguido de subvenciones y contratos. Sin embargo, el convenio está perdiendo presencia frente a subvenciones nominativas (en el ámbito autonómico) y contratos y subvenciones (en las diputaciones y el nivel local). Las aspiraciones futuras del Gobierno autonómico pasan por el concierto, con preferencia (que no exclusividad) para el TSAS (frente al criterio de los cuerpos técnicos de la Administración que abogan por la fórmula del contrato). Sin embargo, para las entidades genera controversias: unas entidades ven los conciertos como una garantía de seguridad y otras como una amenaza, asociada a la libre concurrencia con empresas, y a la inserción correlativa de la actividad del TSAS en un juego competitivo con el sector mercantil, en la práctica asimétrico. En todo caso, el TSAS contempla como inevitable el paso del convenio al concierto pues "los conciertos son transparentes, los convenios son discrecionales" (E16).

En la Comunidad de Madrid no hay regulación específica sobre el concierto social ni está en proceso de regulación, pero en los primeros trabajos técnicos para la elaboración de una nueva Ley de Servicios Sociales ${ }^{3}$ se tiene en cuenta éste como una modalidad prioritaria de cooperación entre Administración e iniciativa privada. Por ahora, en la prestación de servicios y el desarrollo de programas sociales priman la subvención y el contrato, este último de manera creciente dado el mayor peso de la empresa mercantil. Esto implica falta de suficiencia y estabilidad de los ingresos, lo que dificulta la sostenibilidad del TSAS, sobre todo entre las entidades pequeñas y medianas.

Con respecto al papel y el peso de la oferta privada lucrativa frente al TSAS en la prestación de servicios, la diferenciación en todas las CCAA viene supeditada en gran medida por el tipo de servicios y el colectivo al que se le presta (siendo mayores, dependencia o infancia los preferentes). Así, la penetración del sector lucrativo en un ámbito u otro depende de sus expectativas de lucro con la gestión de esos servicios, sobre todo si contemplan copagos por parte de los usuarios finales que eleven su margen de beneficios. "Cuando ha surgido una necesidad siempre ha estado presente el Tercer Sector; pero cuando esa necesidad puede llegar a ser lucrativa siempre se ha desplazado al Tercer Sector" (E23). En los ámbitos con menor potencial de lucro, "los que no son tan deseables y en los que no tienen una capacidad de demanda, de pago, los usuarios finales" (E39) son predominantes las entidades del TSAS. Un

3. Disponible en: https://www.comunidad.madrid/sites/default/files/propuestas_para_una_nueva_ley_de_servicios_sociales_de_la_comunidad_de_madrid.pdf 
factor clave de la mayor o menor penetración del sector mercantil es la fortaleza del TSAS en la región, su organización en entidades de 2ํo 0 3er nivel, la raigambre histórica de colaboración con la correspondiente Administración autonómica (Cataluña, País Vasco) o la orientación política de los gobiernos autonómicos, si bien la tendencia es que en todas las CCAA va creciendo la presencia de las empresas lucrativas, bajo una nueva racionalidad mercantilizadora. La competencia entre TSAS y sector mercantil se da sobre todo en el ámbito de la contratación pública, en cuya adjudicación suele terminar predominando la oferta económica sobre la propuesta técnica o sobre las cláusulas sociales, si bien en las CCAA que abren los conciertos sociales a la empresa lucrativa también va a existir competencia entre ambos sectores. En todo caso, entrevistados de algunas CCAA consideran, como nota positiva, que esta competencia ha favorecido la profesionalización del TSAS, aunque desde otro punto de vista se cree que el TSAS va adquiriendo progresivamente reglas de juego y de gestión propias del management, así como prácticas de mercantilización que distorsionan su identidad.

En la Comunidad Valenciana, la aparición del concierto social para las entidades de iniciativa social ha provocado una diferenciación entre los dos sectores: para el TSAS prevalece el concierto social de centros y servicios (y, para programas, las subvenciones); para el sector mercantil, la contratación pública, si bien con cláusulas sociales. El concierto ha supuesto una ruptura con el modelo mercantilizador del período de gobierno del Partido Popular (19952015), en el que las iniciativas privatizadoras del ámbito sanitario (el modelo Alzira) se incorporaron también al ámbito social, aunque a juicio de los entrevistados el sector mercantil continúa siendo predominante.

En la Comunidad de Madrid, el discurso neoliberal también apareció en las políticas regionales desde 1995 si bien, al no haber habido alternancia en el Gobierno, continua en la actualidad. Bajo esta lógica, se ha tendido a desplazar la gestión de los servicios rentables a la empresa mercantil, mientras que el sector social se encarga de la gestión de servicios menos rentables o donde hay que gestionar problemas y conflictos sociales. Como en otras CCAA, el TSAS considera que "la atención a las personas no puede estar sujeta al precio más bajo" (E14), por lo que abogan por dar mayor peso a las cláusulas sociales (introducidas en la legislación regional durante la legislatura 2015-2019), favoreciendo el valor añadido del sector social, sobre todo según las especialidades de las entidades y empresas concurrentes.

En el caso de Andalucía la normativa establece la prioridad del TSAS en los contratos mediante las cláusulas sociales y en el concierto social, pero también deja la puerta abierta a las empresas lucrativas, que hace que en la práctica prevalezca "una visión mucho más economicista" (E4) en la que la oferta económica es la que decide la concesión de un contrato a la empresa mercantil, y que está teniendo como consecuencia que "Servicios Sociales está copado por empresas que ya sabemos su nombre y apellidos (...) y lógicamente al final se quedarán dos o tres empresas con todo lo social también, que eso es lo que está ocurriendo" (E4).

De forma similar, en la Región de Murcia el sector privado lucrativo gana peso como competidor en precios, pero no en calidad. Al igual que en otras CCAA, se ha extendido sobre todo por los sectores de mayores, dependencia, discapacidad, pero también infancia y tiempo libre. Por sus propias características, el sector lucrativo tiene la capacidad de saltarse las barreras 
que protegen al tercer sector en el acceso a la financiación, en un proceso lento en el que, como explicaban en Andalucía, parece que acabará convirtiéndose en hegemónico.

En Castilla y León, la baja densidad y la dispersión de la población han propiciado que el peso de la iniciativa privada de carácter mercantil en los pequeños núcleos de población en la región sea limitado, por su escasa rentabilidad, permitiendo que el TSAS y, sobre todo, las corporaciones locales conserven o amplíen sus espacios de intervención y de prestación de servicios. Sin embargo, el envejecimiento de la población ha propiciado un aumento en la clientela potencial y un mayor espacio de negocio para las empresas de servicios de tercera edad en los grandes territorios, aunque por otro lado, y como contrapeso, "ha contribuido al desarrollo de un movimiento asociativo de personas mayores y jubilados muy potente en cuanto a número de asociaciones y volumen de recursos" (E36), si bien con una capacidad organizativa y de gestión muy limitada para la prestación de servicios.

La percepción es en cierta medida diferente en las denominadas nacionalidades históricas. Así, en Cataluña, los entrevistados consideran que el sector mercantil está menos extendido que en otras CCAA (salvo en el ámbito de la tercera edad y, territorialmente, en Barcelona por el efecto "capitalidad", que permite generar economías de escala), quizás por la capacidad histórica de organización del TSAS (en la Taula del Tercer Sector y en otras entidades de segundo nivel). Sin embargo, en la competencia con el sector mercantil el TSAS va a salir perdiendo, pues "el precio al final acaba determinando quién gana (ya que) las cláusulas sociales que se aplican al final tienen muy poco peso" (E27).

De la misma manera, en el País Vasco el tradicional modelo mixto de gestión ha reservado un papel preferente en la provisión de servicios sociales a las entidades del TSAS, sobre todo porque históricamente han sido pioneros en la provisión de dichos servicios, y el sector mercantil ha tenido un papel "mucho más residual que en otras comunidades autónomas" (E16). Sin embargo, el crecimiento de contratos y licitaciones, "lo que la normativa, sobre todo europea y de la competencia, quiere" (E18), frente a otras formas de colaboración económica favorece la entrada de empresas mercantiles, que comienzan a ocupar espacios hasta ahora tácitamente reservados al TSAS. Sobre todo, en servicios a la tercera edad y la atención a la dependencia, así como en infancia, ámbitos donde existen mayores oportunidades de negocio y el TSAS no se había consolidado como mayoritario. En las licitaciones y pliegos públicos, el precio se convierte en el criterio decisivo de adjudicación (desplazando en la práctica al criterio de calidad/precio), y hace que en ocasiones disuada a las organizaciones del TSAS a competir vía precio en un concurso, siendo incluso papel mojado las cláusulas sociales. Las entidades defienden la ausencia de lucro como criterio fundamental para establecer el modelo de provisión de servicios, lo que desde el punto de vista de algún entrevistado revela también la acomodación del TSAS del País Vasco a un estatus quo heredado, cercano al clientelismo.

En tercer lugar, en los últimos años ha tenido un impacto importante en la financiación del TSAS la descentralización de la gestión de las subvenciones del 0,7\% del IRPF, de acuerdo con la Sentencia de 16 de diciembre de 2011 del Tribunal Supremo ante el Recurso de Casación 6507/2009 de la Generalitat de Cataluña, en la que se resolvía que la concesión de subvenciones con cargo a la asignación tributaria del IRPF debía ser gestionada por las CCAA, de acuerdo 
con su competencia en materia de asistencia social establecida en el art. 148.1.20 de la Constitución Española. Tras dicha sentencia se estableció un sistema en el que, en diferentes convocatorias, entre el 15-20\% de la recaudación ha correspondido al tramo estatal y entre el 80$85 \%$ al tramo autonómico. En su origen, la puesta en marcha del 0,52\% del IRPF (ahora 0,7\%) actuó de incentivo para la creación de entidades de segundo nivel y la formación de redes de colaboración entre las OTSAS, pues unos de los principales aspectos que se valoraban era la implantación territorial en todo el Estado, "lo que ha ayudado en este país el IRPF a la reorganización del tercer sector" (E35). Desde esta perspectiva, la descentralización del 0,7\% supone deshacer el camino recorrido, la desvertebración territorial del TSAS y la recalibración de sus estructuras de coordinación, así como la dificultad de gestión de las entidades de segundo nivel en base a economías de escala, renunciando a desarrollar proyectos de amplio alcance, con el "riesgo de que se diluya el fin del interés general o interés social" (E10). Ha supuesto, así, para "las organizaciones grandes (...) una amenaza respecto al status quo que tenían, (...) con un aparato administrativo muy importante porque tenía una cantidad de grandes recursos y desde allí se distribuía, y claro, el que distribuye tiene poder" (E40). En el ámbito autonómico, las organizaciones grandes y las federaciones también se han visto afectadas por esa modificación, perdiendo peso en la recepción de fondos frente a las entidades pequeñas y de primer nivel, que antes no podían optar al anterior sistema, generándose una mayor competencia por los recursos, pero también un incremento de la carga de trabajo (sobre todo en entidades que antes recibían financiación vía federaciones, pero no gestionaban el proceso). En el caso de las administraciones autonómicas, el cambio puede interpretarse como positivo por cuanto dota a los fondos de proximidad y permite adaptarlos a sus prioridades técnicas o políticas (o, también, afianzar redes clientelares). La descentralización se ve más positivamente en las comunidades periféricas (Valencia, Andalucía, Cataluña), y más negativamente en Madrid, Murcia y Castilla y León. En todo caso, su aplicación, continuista, no ha respondido a las expectativas generadas, por lo que no se ha distanciado tanto de la financiación anterior como para generar transformaciones significativas en la configuración de los TSAS autonómicos.

Así, en la Comunidad Valenciana hay división de opiniones acerca de si esa descentralización supone atomización o un reparto más equitativo frente a la tensa dualización que existía entre entidades grandes y pequeñas. Algunos entrevistados lo consideran un factor redistributivo, que además permite a la Administración "orientar el 0,7 hacia la coherencia de nuestro modelo de Servicios Sociales" (E42) y ligarlo a las propias necesidades territoriales. Si bien ese cambio se está efectuando de forma lenta, con criterios similares a cuando la financiación era central: "va a continuar favoreciendo a determinadas entidades grandes, pero luego va a darle pequeñas cantidades a muchísimas organizaciones, es decir, una especie de café para todos" (E39). Para un representante de una entidad singular "se produjo una gran disfunción, una gran ruptura o discontinuidad, que representó mucho menos dinero y, sobre todo, ya no está tan estabilizada la cantidad de dinero" (E43). Los profesionales de las entidades pequeñas y medianas lo consideran positivo por el incremento de la financiación, en comparación a cuando se gestionaba desde el ámbito estatal, si bien ha implicado un incremento sustancial del trabajo de gestión y tramitación de las subvenciones: "Ha sido una pesadilla, todo el mes de agosto trabajando en los proyectos de IRPF autonómico" (GF08). 
En Cataluña, dada su singularidad histórica y su tradición nacionalista, la descentralización se considera un avance justo y necesario, que en el plano técnico "puede ser un factor muy potente para diseñar más y mejor las prioridades y la presencia del sector social" (E31). Al igual que en la Comunidad Valenciana, se entiende que la gestión autonómica otorga proximidad, lo cual es una ventaja por el conocimiento de las necesidades y por establecerse un contacto más asequible: "a nosotros nos es más fácil contactar con el ayuntamiento, con la Generalitat" (E30). Sin embargo, aquí tampoco se han visto satisfechas las expectativas existentes en las primeras convocatorias, que "han sido de continuidad con relación a lo que ya existía" (E32) o bien han cambiado algunos criterios sin consultar al sector, que provocó que "entidades que tenían proyectos desde hacía 15 años perdieran el proyecto" (E27), viéndose también más perjudicadas las grandes entidades con sede en Madrid que las medianas y pequeñas.

De un modo similar a las anteriores, en Andalucía la gestión descentralizada de las subvenciones del IRPF se ve positivamente desde un punto de vista teórico, pues otorga a la decisión proximidad y el conocimiento de las intervenciones que se están haciendo en el territorio. Sin embargo, para los entrevistados en la práctica no se están respetando esos criterios, se están retrasando las convocatorias y, desde las entidades grandes, se considera que se está haciendo un sistema de "café para todo el mundo" (E5) en el que se están repartiendo pequeñas cuantías para muchas entidades, pero se está mermando la financiación de proyectos más ambiciosos o de carácter interterritorial.

En lo que respecta a la Comunidad de Madrid, la valoración del impacto de la descentralización del 0,7\% del IRPF es desigual. Para unos entrevistados se trata de un paso hacia la igualdad en la financiación, al abrir la posibilidad de acceso de las pequeñas entidades a un tipo de financiación que hasta recientemente estaba casi reservado en exclusiva para las ONG de gran tamaño; para otros, la descentralización supone un retroceso, por la pérdida de cohesión social a nivel estatal en la medida en que el $0,7 \%$ permitía a algunas entidades abordar proyectos interterritoriales que ahora casi desaparecen y que tenían su epicentro en Madrid.

En la Región de Murcia, hay casi unanimidad en la desestabilización que ha producido. El 0,7 central era una financiación estable y segura: se concedía con antelación, en muchos casos a proyectos similares en distintas CCAA. Desde su descentralización, es un mecanismo de financiación inestable, principalmente por cómo se está implementando: en las convocatorias no se establecen criterios de concesión y ha primado que la financiación llegue a más entidades, en lugar de que llegue a una selección de proyectos bajo criterios técnicos, lo que supone infrafinanciación para la mayoría.

En Castilla y León, a juicio de los entrevistados, la descentralización del 0,7\% del IRPF está teniendo un impacto negativo sobre la cohesión social y territorial de la intervención del TSAS y está resituando el clientelismo hacia el ámbito regional. Este impacto no es uniforme en todas las organizaciones, pues depende del grado de implantación territorial, del tipo de organización (primer o segundo nivel) y de su tamaño. Para la administración regional este cambio de modelo, como en otras CCAA, es positivo ya que, si bien los dos primeros años fueron de continuidad, el nuevo sistema del 0,7 está permitiendo aproximar más la intervención a los territorios y conseguir una mejor integración de los recursos públicos del IRPF en el sistema de protección 
regional. Desde la óptica de las entidades, ha supuesto una disminución de los fondos regionales propios que venían asignando al Tercer Sector y una reorientación de las subvenciones hacia otras prioridades de gasto social: "antes tenían ellos otras ayudas para el tercer sector en su territorio y lo han rebajado bastante" (E35). En el caso de las entidades más pequeñas el efecto puede ser ambivalente. Las que accedían al anterior sistema del 0,7 a través de sus confederaciones estatales podían "descargar la gestión burocrática sobre las entidades de segundo nivel y ahora tienen muchas dificultades" (E35). Por el contrario, para aquellas entidades de menor tamaño que tenían vedado el acceso directo al modelo de IRPF anterior, el cambio es una oportunidad para acceder a los fondos dada la mayor cercanía a la administración.

En el caso de País Vasco, la descentralización del 0.7\% del IRPF no supone ningún impacto debido a las características específicas y diferenciales de la financiación del País Vasco respecto a otros territorios (el llamado "cupo vasco"), que hacen que no haya una convocatoria de subvenciones específica del IRPF en Euskadi ni en sus diputaciones, si bien sí que se podrán notar algunos de sus efectos en entidades que pertenezcan a federaciones estatales en relación con proyectos interterritoriales.

Las diferentes formas de colaboración económica que hemos repasado anteriormente tienen un impacto en el TSAS, modelándolo. Así, se observa que en aquellas comunidades en las que está en auge el concierto social (Comunidad Valenciana y, en cierta medida, Castilla y León), el TSAS se está dotando de una mayor estabilidad financiera y seguridad para desarrollar su trabajo y mantener a sus profesionales, frente a la incertidumbre que supone la subvención. Por el lado negativo, la mayor intensidad en la financiación y la colaboración en modalidades como el concierto social, que implican que los servicios y recursos del TSAS formen parte de la red pública de servicios sociales, pues son de responsabilidad pública, pueden generar dependencias, que limiten a las entidades en tres planos: en el plano técnico, pues se han de supeditar sus conocimientos y estilos de intervención al modelo de intervención de la red pública; en el relacional, por la pérdida de los vínculos que hasta entonces sustentaban a muchas de ellas, como las asociaciones de discapacidad formadas por las propias personas con discapacidad y sus familiares (a cuyas plazas accedían sus asociados); y, en el plano político, al supeditar sus fines (solidarios, reivindicativos, filantrópicos) a los medios, a su propia supervivencia y continuidad: "Buena parte del tercer sector de Servicios Sociales se está convirtiendo en gestor de la Administración. (...) No van a ser entidades de incidencia política en cuanto yo tengo que mantener 30 trabajadores, 50 trabajadores, 80 trabajadores" (E42). Además, puede acentuar la dualidad entre entidades grandes y pequeñas, pues una mayor concertación, o que parte de los recursos de las subvenciones pasen a conciertos, puede suponer afrontar pliegos más complejos sin los equipos profesionales adecuados. A ello se une la excesiva burocracia que implica la licitación y concertación social y, cada vez más, la solicitud de subvenciones. En el caso de estas últimas, su predominio repercute negativamente en la sostenibilidad financiera de las entidades, en sus procesos de intervención y en la estabilidad y continuidad de sus plantillas. Todo ello bajo el acecho, más en unas CCAA que en otras, de la creciente penetración del sector mercantil, bajo una lógica de competencia y mercantilización procedente de las Directivas europeas. 
En las comunidades que cuentan con un modelo de concierto social, como es el caso de la Comunidad Valenciana, éste aporta certidumbre y seguridad económica y jurídica, aunque "siguen estando infrafinanciados" (GF08). El salto es importante, pues en años anteriores "las obligaciones de pago reconocidas por la Administración Pública se podían demorar uno, dos o tres años" (E39). La exclusividad del concierto con entidades de iniciativa social permite diferenciar los espacios de acción del tercer sector y del sector mercantil, reduciendo la competencia entre ambos. Por otro lado, se están observando los riesgos remarcados anteriormente, con repercusiones distintas por colectivos de atención. También el aumento de la carga de trabajo burocrático (en conciertos, pero también en subvenciones) afecta especialmente a entidades pequeñas y medianas, que tienen que dedicar más tiempo y más profesionales a diseñar proyectos y a justificarlos técnica y económicamente, lo que lleva a algunos profesionales a indicar que el sistema de subvenciones llega a ser "perverso" (GF08).

En Castilla y León, el peso que está adquiriendo el concierto social, a expensas de cómo se cierre definitivamente el decreto diseñado a tal fin, es valorado positivamente para la estabilidad y la continuidad de la prestación de servicios por el TSAS. Sin embargo, también en esta comunidad planean incertidumbres relacionadas con su impacto en las estructuras de gestión de recursos (sobre todo en las entidades pequeñas, dado el elevado trabajo burocrático) y con las presiones competitivas del sector mercantil, que pueden afectar también a la propia "idiosincrasia" (E37) del TSAS. "No podemos ser prestadores de todos los servicios, igual a costa de mantener nuestras estructuras; quizás nos estamos metiendo en cosas que no nos corresponden" (E34).

En el caso de País Vasco, el camino recorrido es el inverso. Frente a la estabilidad pretérita de los convenios, y a la espera de la futura regulación de estos y de los conciertos, en la actualidad el recurso a la subvención genera inseguridad en las entidades del TSAS, ya que debilita la estabilidad de las relaciones entre la Administración y el sector, así como la sostenibilidad de la financiación de las entidades, "porque, si yo tengo un convenio de doscientos mil al año (...), es muy difícil que un convenio se rompa; pero una subvención la puedo sacar este año o no la saco al año que viene" (E23). Del mismo modo, el incremento de las licitaciones públicas para la contratación de servicios también genera recelos en las entidades pues consideran que la garantía de la prestación de servicios y de derechos subjetivos podría verse comprometida bajo un régimen de mercado. En todo caso, se observa el desplazamiento de un modelo de colaboración entre AAPP y TSAS basado en su raigambre histórica a un modelo de mayor competitividad, entre entidades y empresas, pero también entre las propias entidades del TSAS (Guinot et al, 2021; Izaguirre, 2021), basado en una lógica mercantil.

En Andalucía, la prevalencia de la subvención sobre otras formas de financiación genera, a juicio de los entrevistados, un sistema "absolutamente perverso" (E1), al que se supedita la estructura y organización de las entidades pues exige liquidez y solvencia económica, al llegar el dinero una vez que la actividad está muy avanzada o incluso terminada y que obliga a una gran carga de trabajo burocrático. Esta inestabilidad en la financiación afecta sobre todo a las plantillas, a su temporalidad y a su salario. Repercute más en las entidades medianas y pequeñas que en las grandes entidades, que suelen tener más diversificada su financiación y cuentan 
tanto con recursos propios como del sector privado. Pero también afecta a los fines de las entidades, algunas de las cuales, para sostener su estructura, cambian el colectivo de intervención en función de las convocatorias de financiación y sus cuantías; y a la propia intervención social.

En la Región de Murcia la preponderancia de la subvención genera también problemas de financiación, como los retrasos en la concesión y el envío de los fondos, lo que hace que el proceso de los proyectos comience en situación muy precaria, sin saber la financiación ni su cuantía. De igual manera, en Cataluña, al no haberse consolidado la legislación sobre el concierto social (publicada con posterioridad a la realización de las entrevistas de este estudio), el predominio de la subvención afecta de forma negativa a la estabilidad de las entidades del TSAS.

En Madrid, el predominio del contrato y del sector mercantil frente al TSAS se considera hasta cierto punto inevitable, por lo que se busca sobre todo un espacio de relación propio con la Administración, fuera de esta lógica competitiva. Así, los entrevistados abogan por mantener la subvención como técnica de fomento del TSAS, si bien que la anualidad del gasto y justificación sean flexibles. A su vez, aspira a la estabilidad de los ingresos públicos mediante convenios a medio plazo o bien conciertos sociales. En todo caso, la sostenibilidad del TSAS madrileño también depende del tamaño de sus entidades, ya que el sector es fuertemente oligopólico, con pocas entidades de tamaño mediano y un excesivo número de entidades de pequeño tamaño.

\section{Participación del TSAS en los asuntos públicos. El papel de las mesas de diálogo y otros espacios de participación}

A la hora de analizar la participación del TSAS en los asuntos públicos, en especial en los espacios de diálogo que se abren entre administraciones autonómicas y TSAS, podemos observar varios factores que condicionan dicha participación. 1) La existencia o no de cauces formales, como las mesas de diálogo; 2) su proceso de constitución, esto es, si fue por iniciativa de la Administración o del TSAS; 3) la distribución geográfica del sector, como, por ejemplo, en lo que concierne a la dialéctica centro-periferia; 4) la cohesión interna del sector y su organización en torno a plataformas representativas; 5) la existencia de organizaciones de segundo nivel (federaciones); 6) la relevancia y naturaleza de canales informales (capital social). Además, también influye la presencia arraigada de una cultura asociativa en las CCAA. Atendiendo a estos seis aspectos podemos explorar la configuración del TSAS de las diferentes CCAA, que otorgan a cada una cierta idiosincrasia o naturaleza distintiva, aunque prevalecen más las convergencias entre ellas. 
Uno de los factores más claros que favorece la relación del TSAS con la Administración es la existencia de canales formales de interlocución, en concreto, las mesas de diálogo. Los propios discursos de los entrevistados plantean cómo a partir de la puesta en marcha de una mesa de diálogo, las relaciones con la Administración cambiaron (Andalucía). En primer lugar, por la legitimación de ciertos canales de interlocución con la Administración; en segundo lugar, por el reconocimiento como interlocutor válido; y, en tercer lugar, por la canalización de las demandas sectoriales a través de dichas mesas.

Aunque, formalmente, en la normativa de la mayoría de CCAA figuran las mesas de diálogo, sólo se han hecho efectivas en País Vasco, Andalucía, Castilla y León, la Región de Murcia y, recientemente, en Madrid. En Cataluña, la Taula del Tercer Sector se ha erigido como representante del TSAS catalán en su relación con la Administración sin haberse formalizado una mesa de diálogo TSAS-Administración. Las CCAA que disponen de mesa de diálogo lo consideran, en términos generales, "un hito, yo creo que ha sido un hito importante" (E46), ya que han mejorado su cohesión interna, y, por otro, que disponen de una relación más fluida y estrecha con la Administración. En ese caso, las entidades sociales se convierten en interlocutores legítimos y legitimados por las AAPP y tienen la posibilidad de intervenir en los asuntos públicos. Sin embargo, un paso previo para canalizar esa interlocución suele ser la creación de una plataforma aglutinante del TSAS que les da ese reconocimiento previo como interlocutor válido. Este es el caso de Andalucía, donde "a raíz de la creación de la Mesa (del Tercer Sector) fue cuando de alguna manera empezamos a exigir un espacio de interlocución en las Administraciones y fruto de ese espacio fue la Mesa del Diálogo Civil” (E5). En Cataluña, desde la creación de la Taula del Tercer Sector, el TSAS dispone de "más fuerza e incidencia política" (E29) a la hora de influir en las diferentes Administraciones, ya que, al ser una sola interlocución, es considerada "patronal entre comillas del tercer sector" (E29). En definitiva, la constitución de una plataforma con voz propia "dota al conjunto del sector social de una capacidad de interlocución con las Administraciones públicas autonómicas y municipales" (E31), que antes no tenía, lo que perciben también las propias entidades (Observatori del Tercer Sector, 2013:18).

En los casos de la Comunidad Valenciana y la Comunidad de Madrid, donde se considera que el TSAS es "más grande, muy heterogéneo y muy atomizado" (E13), la menor capacidad de articulación del TSAS en torno a una gran plataforma, quizás explique su retraso en la puesta en marcha de una mesa de diálogo civil, que en el caso de Madrid se reguló en 2019 y tuvo su primera y única reunión en septiembre de 2020. En la Comunidad Valenciana, aunque "no hay (...) Mesa de Diálogo Civil, a pesar de que la vicepresidenta de alguna forma se comprometió" (E43), se considera clave para que el TSAS pueda ser "reconocido y que se pueda sentar a la hora del diseño de las políticas y a la hora de la disposición de los recursos" (GF08). La ausencia de cauces formales tiende a ser sustituida por cauces informales (aspecto que analizaremos más adelante).

Ahora bien, pese a que las mesas de negociación o diálogo hayan abierto canales de comunicación abiertos y fluidos, donde el TSAS es consultado, no faltan las reticencias, ya que

4. Que sería la plataforma representativa del TSAS en Andalucía, no confundir con la mesa de diálogo institucionalizada, la Comisión Permanente de Diálogo con la Mesa del Tercer Sector de Andalucía. 
dichos canales a veces son "directos, pero poco efectivos" (E30). En Murcia, se ha reunido en pocas ocasiones y hay cierta insatisfacción en el TSAS porque su función es principalmente informativa. En otras CCAA, como Castilla y León, también se observan estas mismas críticas. En esta comunidad el papel de las entidades de iniciativa social en los órganos de interlocución y colaboración con la Administración Pública, a juicio de los entrevistados, es de carácter consultivo y su participación en el diseño y en la configuración de las políticas es limitada. Esta dinámica, que tiende preferentemente hacia el rol prestacional del TSAS, termina ocluyendo el cariz reivindicativo y, como indicaba un entrevistado más arriba, refuerza más un rol del TSAS como patronal antes que como actor de la sociedad civil en defensa de los colectivos a los que se dirige.

En este punto surge el problema de la censura y la autocensura, mayor a medida que se incrementa la dependencia del sector con las AAPP, pues la capacidad para presionar de los responsables políticos, así como la autocensura, por miedo a represalias, implícita o explícitamente ("si continúas por aquí te vas a quedar sin la subvención que tienes" (E28)), puede ser ejercida por los responsables políticos para desactivar cualquier crítica o posición incómoda. En Castilla y León, producto de la dependencia financiera, detrás de lo que es percibido por la Administración como un "ecosistema colaborativo", "de simbiosis" (E37) surge una lógica de subordinación. Esta relación plantea un cierto comportamiento conservador o acrítico del TSAS frente a la Administración, pues "si nos ponernos farruquitos nos sacan del tinglado y ya vienen otros..." (E34). Esta es una realidad más extendida de lo que pareciera, como sugieren otros estudios (Rodríguez Cabrero et al, 2015), y que lleva a preguntarse si la dependencia financiera del sector público implica una reducción de su capacidad reivindicativa.

Otro de los factores a la hora de entender la relación entre el TSAS y la Administración en torno a los espacios de diálogo es la génesis de las mesas de negociación. ¿Cómo se han creado dichas mesas? ¿Son producto de una iniciativa de la Administración o es una reivindicación de las organizaciones del sector? En Andalucía, es la Administración quien pide interlocución para la participación en procesos políticos (generalmente consultivos), por lo que se crea primero la plataforma del TSAS bajo el nombre de Mesa del Tercer Sector de Andalucía y posteriormente una Comisión Permanente para el diálogo con ésta. Estas iniciativas ponen de manifiesto la necesidad de tener una "voz de sector" que, en un contexto de nuevas amenazas comunes (crisis) y con el referente de la Plataforma del Tercer Sector de Acción Social, posibilitan el nacimiento de una estructura formal de interlocución regional. Digamos que desde la Administración se busca un interlocutor y ven desde el sector la necesidad de "crear un marco de referencia, de discurso y de relato" (E6).

Igualmente, en Castilla y León, el proceso se constituyó de arriba-abajo lo cual ha impuesto ciertas dinámicas como es el hecho de que la planificación, la voz cantante, se lleve desde la Administración. "La Administración planifica cómo quiere que sea el trabajo del tercer sector y ellas han entrado un poquito en este plegamiento" (E36).

En Cataluña, el carácter pionero de la Taula del Tercer Sector, creada en 2003, ha marcado los pasos de la interlocución con la Administración, sin hacer necesario el recurso a una mesa exclusiva para el diálogo del TSAS y la Administración, sino participando en diferentes órganos 
consultivos de la Generalitat, el Ayuntamiento de Barcelona y la Diputación. Los informantes lo consideraban uno de los hitos más importantes para entender la evolución del TSAS catalán y su propia idiosincrasia.

Un caso especial es el de País Vasco. Si bien la Administración autonómica impulsó la creación de una mesa de negociación y diálogo, la cohesión interna del sector era ya muy fuerte, pero en el interior de las tres provincias históricas: Vizcaya, Álava y Guipúzcoa.

Esto último nos conduce al siguiente factor, la configuración geográfica del sector. En el País Vasco, los servicios sociales siempre han tenido una adscripción de responsabilidad muy territorializada, construyéndose "desde abajo", a partir de las administraciones locales (Ayuntamientos y Diputaciones). Este hecho ha determinado que las entidades hayan articulado sus relaciones a partir del territorio. Este hecho, a nuestro entender, hace que la percepción de la Mesa de Diálogo Civil, pese a constituirse desde arriba, es valorada como un instrumento productivo de interlocución, más allá de la mera consulta o de su papel en la distribución de recursos, con una función de diagnóstico de necesidades e identificación de objetivos. "Hay un diálogo bastante estrecho sobre políticas en términos de información y también de señalamiento de necesidades por parte del sector (...), ahí no solamente voy, capto recursos y ya está" (E16).

No obstante, la distribución geográfica más común es la constituida por la dialéctica centro-periferia, que interroga directamente a la cohesión interna del TSAS. Este aspecto, unido al tamaño de las organizaciones, presente de manera significativa en la Comunidad de Madrid, nos ayuda a explicar cómo hay diferentes velocidades en la composición de las plataformas sectoriales. Un ejemplo muy claro de cómo se combinan ambas variables, tamaño y dialéctica centro-periferia, es el de Cataluña: La constitución de la Taula del Tercer Sector se produce entre todas las grandes organizaciones, "no hubo ninguna entidad grande que se quedara fuera, que yo recuerde" (E26). Esta dinámica provoca ciertos recelos de las pequeñas organizaciones que tienden a ser un obstáculo para la cohesión interna global, como se puede observar en la Comunidad Valenciana, cuando se intenta constituir la Plataforma del Tercer Sector: "las organizaciones veían con recelo un poquito eso. Y es que las pequeñas han tenido un discurso victimista respecto de las grandes que nos llevamos todo" (E40).

Al establecerse las grandes organizaciones en las capitales, en el caso de Cataluña en Barcelona, el eje tamaño se solapa con el eje centro-periferia. Mientras que el discurso desde el centro es inclusivo, desde la periferia el discurso difiere absolutamente. Así, en uno de los grupos focales, compuesto por responsables de organizaciones casi todas ellas fuera de Barcelona, no tenían ningún conocimiento de lo que era la Taula. Solo una componente del grupo había tenido algún contacto: "tuve un contacto hace ya años... no sé si 5 o 6 años, fui a una mesa redonda que se hizo aquí en Tarragona sobre el tercer sector, sobre la pobreza, y entonces al terminar la mesa redonda se acercaron los de la Taula y les dije que claro que por supuesto que estábamos dispuestos a colaborar, a entrar, que me informasen qué era y entonces recuerdo que vinieron al comedor tres o cuatro representantes de esta Taula, hicimos la entrevista, les volcamos toda la información de lo que nosotros estábamos trabajando y dijimos que estábamos interesados, pero no volvimos a tener respuesta" (GF10). La dispersión geográfica, por tanto, no ayuda a cohesionar al TSAS y a que exista una voz efectivamente representativa de la diversidad del 
sector, como sucede también en Comunidad Valenciana, donde hay un centro (Valencia), y dos provincias más periféricas, Alicante y sobre todo Castellón. Lo que hace preguntarnos en qué medida la plataforma representa sobre todo a las grandes entidades, a las que ocupan posiciones de centralidad o de poder.

Además, en un segundo nivel del TSAS, donde el sector se ha ido organizando "más que por entidades por federaciones" (E29) que aglutinan a entidades que trabajan con temas o colectivos específicos (infancia, discapacidad, exclusión social, etc.), se observa en las CCAA una asimetría de la colaboración entre el TSAS y la Administración Pública por colectivos o áreas de intervención (Izquieta et al, 2007). Así, en Castilla y León, de acuerdo con los entrevistados, "cada uno se lleva según la fuerza que tenga" (E33). Esa fuerza o capacidad de influencia depende de la capacidad de organización en grandes plataformas, de tejer redes entre entidades y del grado de cohesión en sus objetivos y reivindicaciones. Esa capacidad de organización en plataformas depende a su vez de: a) las inercias gerencialistas de las organizaciones y de los directivos que las lideran (esto es, de su capital social); b) la capacidad de autorrepresentación de los usuarios en la organización, en particular, de la capacidad organizativa de los afectados directos y de sus familias (es decir, de su cultura asociativa); c) la capacidad instalada en la prestación de servicios, y d) la existencia de un marco jurídico estable y seguro para las organizaciones. En general en todas las CCAA existe un amplio consenso en que están más arraigados en las entidades de discapacidad. Así, para los entrevistados de Castilla y León, explica su capacidad de ejercer como potente lobby comparado con otras entidades orientadas específicamente a la inclusión o a las personas mayores. Incluso, en la Comunidad de Madrid, pese a que, como hemos señalado, el TSAS se caracteriza por su "debilidad estructural" (E13) a causa de su atomización y a la baja representación de entidades de tamaño intermedio, el sector de la discapacidad está muy consolidado, con fuertes plataformas de apoyo y una importante presencia en la economía social.

En la Comunidad Valenciana, cuya situación estructural en términos organizativos es similar a la de la Comunidad de Madrid, ven que esa creación de plataformas de segundo nivel dirigidas a colectivos específicos es una alternativa para la visibilidad e incidencia, pero mientras en colectivos como el mencionado anteriormente ya cuentan con una larga trayectoria, en otros están empezando a formarse. "Tenemos una plataforma de segundo nivel que sería la Red de Entidades para la Atención de Personas Sin Hogar que no está constituida como Federación porque realmente notamos esa falta de visibilidad y de unidad hacia el trabajo que las entidades que engloban esa red están haciendo, entonces el paso siguiente (...) va a ser constituirlas en Federación" (GF08).

Otro de los factores detectados es la relevancia y naturaleza de los canales informales de comunicación del TSAS con la Administración o, utilizando la terminología de Pierre Bourdieu (1985: 248), su capital social. En términos generales, cuando los canales formales de comunicación son débiles, estos son sustituidos por canales informales donde prevalecen las relaciones personales. En la Comunidad Valenciana, en la medida en que se han creado cauces de interlocución colectiva con la Administración, sobre todo desde 2015, por iniciativa de una u otra de las partes, se ha mejorado la calidad de esa comunicación, evitando caer en el 
clientelismo de legislaturas anteriores. "Tras los intentos de relacionarse cada iniciativa social y cada sector de manera individual y particular con las Administraciones públicas, que daba pie al amiguismo y al clientelismo, se asiste actualmente a dos medidas interesantes: por una parte, a la defensa de los intereses comunes por parte del TSAS mediante órganos colegiados, coordinadoras y plataformas; y, por otra, mediante la publicidad y transparencia de los criterios" (E41).

No obstante, el capital social también es un factor a tener en cuenta cuando los canales formales están consolidados. Las relaciones TSAS/Administración también se sustentan en medios informales, que podrían tener incluso mayor significación que los formales. Es relativamente habitual que estas relaciones se apoyen en la existencia de vínculos personales, que incluso dan lugar a flujos de ida y vuelta de actores entre el TSAS y la Administración. En Castilla y León, por ejemplo, las mesas de diálogo civil son el principal instrumento formal de interlocución entre el Tercer Sector y la Administración, pero, según los entrevistados, es de gran importancia el capital relacional entre las personas representativas del TSAS y altos cargos políticos y técnicos de la Administración. Así, podemos afirmar que las relaciones personales importan, incluso más que los canales institucionales formales: "otras Comunidades Autónomas tienen mesa de diálogo civil y no tienen esta relación" (E34). Un aspecto positivo es que dichas relaciones han conseguido dar estabilidad a la relación TSAS/Administración en momentos de crisis. "Es una relación extremadamente fluida y de absoluta lealtad por ambas partes, y eso se ha sujetado hasta las máximas crisis" (E34).

En el caso de País Vasco, los canales informales, por la propia idiosincrasia y constitución del sector, como hemos analizado anteriormente, precedían a los formales. Es relativamente habitual que las relaciones formales se apoyen en esos vínculos personales, y en los ya mencionados flujos de ida y vuelta de actores entre el TSAS y la Administración, lo que da lugar a que "en ocasiones, quienes acaban trabajando en instituciones, en cargos intermedios, técnicos o políticos [de la Administración], también son personas que provienen del Tercer Sector" (E24).

Por último, cabría mencionar un factor que también influye en las relaciones entre la Administración y el TSAS, que es el arraigo histórico de una cultura asociativa, ya sea de tendencia voluntaria, relacional o cooperativa, que encontramos en cada territorio. Así, en Cataluña los informantes dan mucha importancia a la movilización de las bases, al voluntariado. Dicha cultura no solo caracteriza a las entidades de acción social, sino que está muy extendida. Así, existen "asociaciones desde culturales hasta pasando por todo lo que es ocio y tiempo libre de chicos, chicas, preservación del medioambiente..." (E29), lo que hace "muy fácil encontrar gente que colabora, gente que te ayude, incluso pequeñas empresas locales y municipales" (GF10), o tener capacidad de financiación propia a través de aportaciones de particulares, lo que reduce su dependencia de las AAPP.

Esta cultura asociativa puede también centrarse en elementos relacionales, como en las entidades de discapacidad, formadas por familias y personas que se unen para dar respuesta a una necesidad común, lo que refuerza su capacidad de movilización. Se encuentra presente en todas las CCAA. Así, en el País Vasco se pone énfasis al valor del trabajo en común de las entidades de discapacidad. 0 en Castilla y León, cuya unión le permite tener una capacidad 
de presión extra ante la Administración: "no tienen ningún problema, si el consejero se resiste, a poner a 200 personas con silla de ruedas en la plaza" (E36). En otras CCAA, como Murcia o Comunidad Valenciana, las cooperativas han tenido una gran fortaleza en el ámbito rural y agrario y han influido en la cultura asociativa de ambos territorios.

\section{Conclusiones}

El TSAS y las AAPP, como hemos podido ver en las anteriores páginas, desarrollan una cooperación necesaria, pero dependiente en términos económicos y financieros. Aunque diferentes trabajos muestran que el peso de la financiación pública ha disminuido entre el período de crisis y postcrisis, del 61,3\% en 2008 al 41,4\% en 2018 (P0AS, 2020), en muchas entidades, sobre todo pequeñas y medianas, ésta continúa siendo la vía de financiación principal. Por otro lado, la Administración también ha dependido hasta ahora del TSAS para dar respuesta a las necesidades sociales de determinados colectivos vulnerables o en riesgo de exclusión, pero la progresiva incorporación del sector mercantil a la gestión de servicios sociales, a medida que éstos han empezado a ser susceptibles de rentabilizarse económicamente, puede transformar la relación entre ambas esferas. En todo caso, lo que se observa es una creciente penetración de una lógica mercantil en la prestación de servicios sociales en todas las CCAA, si bien en cada una de ellas con diferentes ritmos e intensidades. Una racionalidad mercantilizadora que no solo se reduce a la contratación de servicios (primando el precio por encima de la calidad o de las cláusulas sociales) sino que, como criterio objetivable para la asignación de fondos o recursos, también se traslada a los conciertos e incluso a las subvenciones, bajo lógicas de competitividad propias de la esfera del mercado y que obligan progresivamente a las entidades del TSAS a adoptar formas organizativas propias del management que, como decíamos, pueden llegar a distorsionar su propia identidad.

En esa tensión existente en el trinomio TSAS-AAPP-mercado, se observa una lucha (aunque a veces también se dan alianzas) en la que el TSAS trata, no ya de buscar una hegemonía, sino de marcar su propio espacio en el campo en disputa, en términos de Bourdieu (1997: 49), que son hoy día los servicios sociales. Y uno de los marcos en los que opera esa lucha se encuentra en la legislación. Reconocer formalmente el papel preferencial del TSAS como prestador de servicios o dotarle de una legitimidad como interlocutor válido con la Administración son clave para la propia supervivencia del TSAS, para definir su propio espacio en el ámbito de los servicios sociales.

Así, podríamos encontrarnos una legislación posibilista o limitadora, en la medida en que favorece o dificulta el desarrollo y consolidación del TSAS. Del análisis normativo se infiere que, aunque todas las CCAA muestran tendencias similares (reconocimiento del TSAS en la prestación de servicios sociales, regulación de los conciertos sociales, creación de mesas de diálogo u otros canales de interlocución con el TSAS), los ritmos de unas y otras son distintos, así como la mayor o menor prioridad que se da al TSAS, por ejemplo, en los conciertos sociales. Mientras que en Comunidad Valenciana estos se restringen a las entidades de iniciativa social 
(propiciando dos espacios diferenciados para la prestación de servicios al sector mercantil y al tercer sector), en otras CCAA analizadas que ya lo han regulado o están en proceso lo abren también al sector mercantil, si bien con preferencia para el TSAS, lo que evita riesgos de que sea recurrido por las empresas en los tribunales. En todo caso, ese reconocimiento del TSAS se está dando en todas las nuevas normas autonómicas y, aunque algunas lideran procesos y otras van por detrás, se evidencian transferencias de preceptos normativos de las primeras en las segundas. Se trata, al fin y al cabo, de dar cabida al TSAS en un marco mercantilizador, que es ante todo ideológico, pero que tiene en la legislación, y en concreto en la Directiva europea 2014/24/UE, de 26 de febrero sobre contratación pública, su punta de lanza.

Es evidente que la legislación es un dispositivo performativo, o que al menos pretende serlo, y que por lo tanto puede modificar la constitución y fisonomía del TSAS. Así pues, las formas de colaboración económica entre TSAS y Administración tienden a buscar la estabilidad, evolucionando desde la financiación muchas veces discrecional de los convenios y las subvenciones nominativas, a formas de financiación cada vez más sujetas a la racionalidad formal 0 burocrática, y competitiva: los conciertos sociales, la contratación pública o la subvención en concurrencia competitiva. La tendencia es generalizada en todas las CCAA, aunque con ritmos distintos en los que influye el perfil político de las administraciones, el tamaño del TSAS y su capacidad de influencia, su raigambre histórica, la mayor o menor penetración del sector mercantil, etc. En todas las CCAA sigue creciendo el peso del mercado en la prestación de servicios, de ahí que para el TSAS resulte determinante cuál es el papel que la legislación otorga a este sector en los conciertos sociales, sobre los que proyectan sus expectativas de futuro. Valga apuntar, como ya señalábamos, que el precio a pagar por el TSAS para garantizar su sostenibilidad pasa por perder parte de su identidad, ya sea en el plano técnico, supeditándose al modelo de intervención de la red pública; relacional, por la pérdida de los vínculos que hasta entonces sustentaban a muchas de ellas, como las asociaciones de discapacidad, o el político, al supeditar sus fines reivindicativos o de defensa de los colectivos a los que representan, a las cadenas de hierro (Mitchels, 1979: 155) de su dependencia financiera.

Es al fin y al cabo esta realidad la que ha llevado al TSAS a organizarse mediante plataformas representativas, con el antecedente histórico de la Taula del Tercer Sector en Cataluña (o, más allá, del CERMI como plataforma representativa del sector de la discapacidad), y a su vez reclamar su papel de interlocutor válido, con una voz única, en los órganos consultivos y los espacios que la Administración abre a la participación de la sociedad civil. La tendencia nuevamente en todas las CCAA es la institucionalización de estos, habitualmente bajo el nombre de mesas de diálogo, pero también cuentan con ritmos distintos en su creación. Las diferencias temporales entre las CCAA analizadas en la creación de estos espacios dependen, fundamentalmente, de la existencia previa de un sector más o menos organizado (en torno a plataformas), las relaciones formales e informales entre TSAS y Administración que existían previamente, la distribución y dispersión geográfica del TSAS, la existencia y el peso de las organizaciones de segundo nivel o la raigambre histórica de una cultura asociativa en cada comunidad.

Sin embargo, del análisis de las entrevistas con actores significativos del TSAS, lo que se desprende es que estas plataformas en muchas ocasiones tienden a ejercer más un papel de 
"patronal entre comillas del tercer sector" (E29), de defensa de los intereses de las entidades, más que de defensa de los colectivos a los que representan, y que las mesas de diálogo civil sirven para reforzar esa dinámica, que pone en primer plano su sostenibilidad y sus intereses como organizaciones frente a los fines que las constituyeron.

Contribución de cada autor/a: Eduardo Díaz Velázquez: Introducción y metodología, grupos focales, análisis cualitativo y elaboración de conclusiones. Santiago García Campá: análisis normativo. Luis Mancha San Esteban: entrevistas y grupos focales y análisis cualitativo.

Financiación: Estudio financiado por el Plan Estatal de Investigación del Ministerio de Economía, Industria y Competitividad (ref CS02017-85486-P).

\section{Bibliografía}

AGUIAR, F. \& PÉREZ, M. (1995): “Aproximación al sector voluntario andaluz en el ámbito de los servicios sociales". En Sarasa \& Moreno (eds.), El estado del bienestar en la Europa del Sur, Madrid, CSIC- Politeya, 215-238.

BOURDIEU, P. (1985): “The forms of capital”. En Richardson, J.G. (ed.) (1985), Handbook of theory and research for the sociology of education, Nueva York: Greenwood, 241-258.

BOURDIEU, P. (1997): Razones prácticas. Sobre la teoría de la acción, Barcelona: Anagrama.

COMISIÓN EUROPEA (2010): Comunicación "La Plataforma Europea contra la Pobreza y la Exclusión Social: Un marco europeo para la cohesión social y territorial”, COM(2010) 758 final de 16 de diciembre de 2010. https://goo.gl/y1ttMh

FRESNO, J.M. (2021): “Concierto Social y cooperación Administraciones Tercer Sector", VIII Congreso de la Red Española de Política Social, Bilbao, 15 y 17 de marzo de 2021.

FUNDACIÓN LUIS VIVES (2010): Anuario del Tercer Sector de Acción Social en España, Madrid, FLV.

FUNDACIÓN LUIS VIVES (2012): Anuario del Tercer Sector de Acción Social en España, Madrid, FLV.

GARCÍA DELGADO J.L. (dir.) (2005): La economía social en España. Criterios y propuestas, Madrid, Fundación ONCE.

GUINOT, C., ARRIETA, F. \& FERRÁN, A. (2021): “El 'modelo guipuzcoano' a debate: ¿Singular o Refractario?", VIII Congreso de la Red Española de Política Social, Bilbao, 15 y 17 de marzo de 2021. 
HERRERA GÓMEZ (2001): “Las políticas sociales en el Welfare mix", REIS: Revista Española de Investigaciones Sociológicas, 96, 71-94.

IZAGUIRRE, A., SÁNCHEZ, V. \& ZÚÑIGA, M. (2021): "Analizando las vías de relación entre la Administración pública y el tercer sector: Reflexiones desde el contexto gipuzkoano", VIII Congreso de la Red Española de Política Social, Bilbao, 15 y 17 de marzo de 2021.

IZQUIETA ETULAIN, J.L, CALLEJO GONZÁLEZ, J.J., PRIETO LOBATO, J.M \& DE LA ROSA, P. (2007): "Administraciones públicas y organizaciones de voluntariado: contenido y alcance de sus interacciones", Papers, 86, 55-71.

MARBÁN, V., PÉREZ, M. \& RODRÍGUEZ, G. (2020): “Current challenges and prospective analysis of the third sector of social action (TSSA) in Spain", CIRIEC-España, Revista de Economía Pública, Social y Cooperativa, 98, 95-126. DOI: 107203/CIRIEC-E.98.1538

MARBÁN, V. \& RODRÍGUEZ CABRERO, G. (2013): "Sistemas mixtos de protección social. El tercer sector en la producción de bienestar", Presupuesto y Gasto Público, 71, 61-82.

MITCHELS, R. (1979). Los partidos políticos. Un estudio sociológico de las tendencias oligárquicas de la democracia moderna, Buenos Aires, Amorrortu Editores.

PLATAFORMA DE ONG DE ACCIÓN SOCIAL (POAS) (2015): El Tercer Sector de Acción Social en 2015: impacto de la crisis, Madrid: POAS.

PLATAFORMA DE ONG DE ACCIÓN SOCIAL (POAS) (2020): El Tercer Sector de acción Social en España 2019. Nuevos horizontes para un nuevo contexto sociopolítico, Madrid: POAS. Disponible en https://www.plataformaong.org/tercer-sector-accion-social.php

PRIETO, J., RODRÍGUEZ, C. \& DE LA ROSA, P. (2019): "Las relaciones entre administraciones públicas y Tercer Sector en el marco de las políticas de inclusión social en Castilla y León", Investigaciones Regionales - Journal of Regional Research, 44, 63-79.

RODRÍGUEZ, G., FANTOVA, F., MARBÁN, V. \& ZUBERO, I. (2015): Análisis prospectivo sobre los retos actuales y futuros del Tercer Sector de Acción Social. Parte II: Los retos del Tercer Sector de Acción Social, Madrid: POAS. Disponible en: http://www.plataformaong.org/ciudadaniaactiva/tercersector/analisis_prospectivo_retos_del_TSAS_parte_2.pdf

RODRÍGUEZ, G. \& MARBÁN, V. (2015): “Posicionamiento y relaciones entre el TSAS, el sector público y la esfera mercantil”. En: Rodríguez, G., Fantova, F., Marbán, V. \& Zubero, I., Análisis prospectivo sobre los retos actuales y futuros del Tercer Sector de Acción Social. Parte II: Los retos del Tercer Sector de Acción Social. Situación actual y tendencias de futuro del TSAS en España, Madrid: POAS. Disponible en: https://www.plataformaong.org/ARCHIVO/documentos/ biblioteca/analisis_prospectivo_retos_del_TSAS_parte_2.pdf 
SALINAS, F., RUBIO, M.J. \& CEREZO, I. (2001): La evolución del Tercer Sector hacia la Empresa Social. Madrid: Plataforma para la Promoción del Voluntariado en España.

\section{Referencias legislativas}

Comunidad Autónoma de Andalucía, Consejería de igualdad y políticas sociales. Decreto 98/2016, de 10 de mayo, por el que se crea la Comisión Permanente de Diálogo con la Mesa del Tercer Sector de Andalucía. Boletín Oficial de la Junta de Andalucía, de 25 de mayo de 2016, 98, 60 a 62. Recuperado de https://www.juntadeandalucia.es/boja/2018/39/B0JA18-03900018-3332-01_00130727.pdf.

Comunidad Autónoma de Andalucía, Consejería de igualdad y políticas sociales. Decreto $41 / 2018$, de 20 de febrero, por el que se regula el concierto social para la prestación de los servicios sociales. Boletín Oficial de la Junta de Andalucía, de 23 de febrero de 2018, 39, 45 a 62. Recuperado de https://www.juntadeandalucia.es/boja/2018/39/B0JA18-039-000183332-01_00130727.pdf.

Comunidad Autónoma de Andalucía, Parlamento de Andalucía. Ley 4/2006, de 23 de junio, de Asociaciones de Andalucía. Boletín Oficial del Estado, de 4 de agosto de 2006, 185, 29306 a 29312. Recuperado de https://www.boe.es/boe/dias/2006/08/04/pdfs/A29306-29312.pdf.

Comunidad Autónoma de Andalucía, Parlamento de Andalucía. Ley 9/2016, de 27 de diciembre, de Servicios Sociales de Andalucía. Boletín Oficial del Estado, de 21 de enero de 2017, 18, 5415 a 5487. Recuperado de https://www.boe.es/boe/dias/2017/01/21/pdfs/ BOE-A-2017-657.pdf.

Comunidad Autónoma de Castilla y León, Cortes de Castilla y León. Ley 16/2010, de 20 de diciembre, de servicios sociales de Castilla y León. Boletín Oficial del Estado, de 8 de enero de 2011, 7, 1756 a 1803. Recuperado de https://www.boe.es/boe/dias/2011/01/08/pdfs/ BOE-A-2011-402.pdf.

Comunidad Autónoma de Castilla y León, Cortes de Castilla y León. Ley 4/2018, de 2 de julio, de ordenación y funcionamiento de la red de protección e inclusión a personas y familias en situación de mayor vulnerabilidad social o económica en Castilla y León. Boletín Oficial del Estado, de 10 de agosto de 2018, 193, 80623 a 80652. Recuperado de https://www.boe.es/boe/ dias/2018/08/10/pdfs/BOE-A-2018-11415.pdf.

Comunidad Autónoma del País Vasco, Departamento de empleo y asuntos sociales. Decreto 283/2012, de 11 de diciembre, por el que se constituye y regula la Mesa del Diálogo Civil. Boletín Oficial del País Vasco, de 24 de diciembre de 2012, 248, 1 a 9. Recuperado de https://www. lehendakaritza.ejgv.euskadi.eus/y22-bopv/es/bopv2/datos/2012/12/1205791a.pdf. 
Comunidad Autónoma del País Vasco, Parlamento Vasco. Ley 27/1983, de 25 de noviembre, de Relaciones entre las Instituciones Comunes de la Comunidad Autónoma y los Órganos Forales de sus Territorios Históricos. Boletín Oficial del Estado, de 17 de abril de 2012, 92, 30060 a 30076. Recuperado de https://www.boe.es/boe/dias/2012/04/17/pdfs/BOE-A-2012-5193. pdf.

Comunidad Autónoma del País Vasco, Parlamento Vasco. Ley 12/2008, de 5 de diciembre, de Servicios Sociales del País Vasco. Boletín Oficial del Estado, de 7 de octubre de 2011, 242, 105335 a 105396. Recuperado de https://www.boe.es/boe/dias/2011/10/07/pdfs/ BOE-A-2011-15726.pdf.

Comunidad Autónoma del País Vasco, Parlamento Vasco. Ley 6/2016, de 12 de mayo, del Tercer Sector Social de Euskadi. Boletín Oficial del Estado, de 23 de junio de 2016, 151, 44935 a 44952. Recuperado de https://www.boe.es/boe/dias/2016/06/23/pdfs/BOE-A-2016-6085. pdf.

Comunidad Autónoma del País Vasco, Parlamento Vasco. Ley 9/2016, de 2 de junio, de Fundaciones del País Vasco. Boletín Oficial del Estado, de 23 de junio de 2016, 151, 44964 a 45001. Recuperado de https://www.boe.es/boe/dias/2016/06/23/pdfs/B0E-A-2016-6088.pdf.

Comunidad de Madrid, Asamblea de Madrid. Ley 11/2003, de 27 de marzo, de Servicios Sociales de la Comunidad de Madrid. Boletín Oficial del Estado, de 2 de julio de 2003, 157, 25487 a 25505. Recuperado de https://www.boe.es/boe/dias/2003/07/02/pdfs/A25487-25505.pdf.

Comunidad de Madrid, Vicepresidencia, Consejería de presidencia y portavocía del Gobierno. Decreto 56/2019, de 18 de junio, del Consejo de Gobierno, por el que se crea la Mesa de Diálogo Civil de la Comunidad de Madrid con el Tercer Sector de Acción Social. Boletín Oficial de la Comunidad de Madrid, de 21 de junio de 2019, 146, 110 a 117. Recuperado de https://www. bocm.es/boletin/CM_Orden_BOCM/2019/06/21/BOCM-20190621-26.PDF.

Comunidad Valenciana, Cortes Valencianas. Ley 3/2019, de 18 de febrero, de la Generalitat, de Servicios Sociales Inclusivos de la Comunitat Valenciana. Boletín Oficial del Estado, de 12 de marzo de 2019, 61, 23249 a 23349. Recuperado de https://www.boe.es/boe/ dias/2019/03/12/pdfs/BOE-A-2019-3489.pdf.

Comunidad Valenciana, Vicepresidencia y Consejería de igualdad y políticas sociales. Decreto 181/2017, de 17 de noviembre, del Consell, por el que se desarrolla la acción concertada para la prestación de servicios sociales en el ámbito de la Comunitat Valenciana por entidades de iniciativa social. Diario Oficial de la Comunidad Valenciana, de 23 de diciembre de 2017, 8.197, 48.245 a 48.266. Recuperado de https://dogv.gva.es/datos/2017/12/23/pdf/2017_11941. pdf. 
España, Cortes Generales. Ley 50/2002, de 26 de diciembre, de Fundaciones. Boletín Oficial del Estado, de 27 de diciembre de 2002, 310, 45504 a 45515. Recuperado de https://www.boe.es/ boe/dias/2002/12/27/pdfs/A45504-45515.pdf.

España, Cortes Generales. Ley Orgánica 1/2002, de 22 de marzo, reguladora del Derecho de Asociación. Boletín Oficial del Estado, de 26 de marzo de 2002, 73, 11981 a 11991. Recuperado de https://www.boe.es/boe/dias/2002/03/26/pdfs/A11981-11991.pdf.

España, Cortes Generales. Ley 38/2003, de 17 de noviembre, General de Subvenciones. Boletín Oficial del Estado, de 18 de noviembre de 2003, 276, 40505 a 40532. Recuperado de https:// www.boe.es/boe/dias/2003/11/18/pdfs/A40505-40532.pdf.

España, Cortes Generales. Ley 43/2015, de 9 de octubre, del Tercer Sector de Acción Social. Boletín Oficial del Estado, de 10 de octubre de 2015, 243, 94844 a 94852. Recuperado de https:// www.boe.es/boe/dias/2015/10/10/pdfs/BOE-A-2015-10922.pdf.

España, Cortes Generales. Ley 9/2017, de 8 de noviembre, de Contratos del Sector Público, por la que se transponen al ordenamiento jurídico español las Directivas del Parlamento Europeo y del Consejo 2014/23/UE y 2014/24/UE, de 26 de febrero de 2014. Boletín Oficial del Estado, de 9 de noviembre de 2017, 272, 107714 a 108007. Recuperado de https://www.boe.es/boe/ dias/2017/11/09/pdfs/BOE-A-2017-12902.pdf.

Generalitat de Cataluña, Departamento de trabajo, asuntos sociales y familias. Decreto 69/2020, de 14 de julio, de acreditación, concierto social y gestión delegada en la Red de Servicios Sociales de Atención Pública. Diario Oficial de la Generalitat de Cataluña, de 16 de julio de 2020, 8.178, 1 a 23. Recuperado de https://portaldogc.gencat.cat/utilsEADOP/ PDF/8178/1804995.pdf.

Generalitat de Cataluña, Parlamento de Cataluña. Ley 12/2007, de 11 de octubre, de Servicios Sociales de Cataluña. Boletín Oficial del Estado, de 6 de noviembre de 2007, 266, 45490 a 45519. Recuperado de https://www.boe.es/boe/dias/2007/11/06/pdfs/A45490-45519.pdf.

Región de Murcia, Asamblea General de Murcia. Ley 3/2021, de 29 de julio, de Servicios Sociales de la Región de Murcia. Boletín Oficial de la Región de Murcia, de 30 de julio de 2021, 174, 22707 a 22771. Recuperado de: https://www.borm.es/services/anuncio/ano/2021/numero/5110/pdf?id=795787

Región de Murcia, Consejería de Familia e Igualdad de Oportunidades. Decreto n.․10/2018, de 14 de febrero, por el que se establece el régimen jurídico de los conciertos sociales en la Región de Murcia en los servicios sociales especializados en los sectores de personas mayores y personas con discapacidad. Boletín Oficial de la Región de Murcia, de 28 de febrero de 2018, 49, 5023 a 5040. Recuperado de: https://www.borm.es/borm/documento?obj=anu\&id=765336 
Región de Murcia, Consejería de Familia e Igualdad de Oportunidades. Orden de 9 de septiembre de 2015, por la que se crea la Comisión de Trabajo "Mesa de Apoyo al Tercer Sector" y se establece su régimen de funcionamiento. Boletín Oficial de la Región de Murcia, de 12 de febrero de 2015, 211, 32931 a 32934. Recuperado de: https://www.borm.es/borm/documento?obj=anu\&id=736037

Unión Europea, Parlamento Europeo y Consejo. Directiva 2014/23/UE, del Parlamento Europeo y del Consejo, de 26 de febrero de 2014, relativa a la adjudicación de contratos de concesión. Diario Oficial de la Unión Europea, de 28 de marzo de 2014, L 94, 1 a 64. Recuperado de https://www.boe.es/doue/2014/094/L00001-00064.pdf.

Unión Europea, Parlamento Europeo y Consejo. Directiva 2014/24/UE, del Parlamento Europeo y del Consejo, de 26 de febrero de 2014, sobre contratación pública y por la que se deroga la Directiva 2004/18/CE. Diario Oficial de la Unión Europea, de 28 de marzo de 2014, L 94, 65 a 242. Recuperado de https://www.boe.es/doue/2014/094/L00065-00242.pdf. 